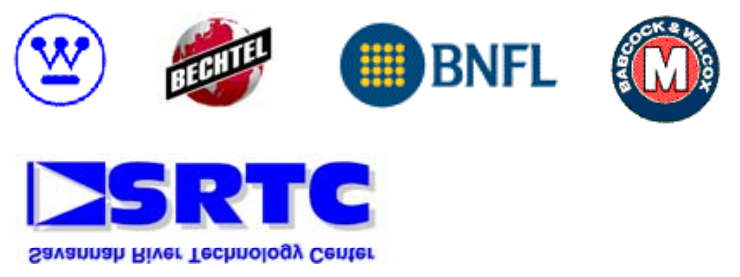

WSRC-TR-2002-00534

\title{
AIR EMISSION PROJECTIONS DURING \\ ACID CLEANING OF F-CANYON WASTE HEADER \#2 (U)
}

December 12, 2003

A. S. Choi

Savannah River Technology Center Westinghouse Savannah River Company Aiken, SC 29808 
This document was prepared in conjunction with work accomplished under Contract No. DE-AC09-96SR18500 with the U. S. Department of Energy.

\section{DISCLAIMER}

This report was prepared as an account of work sponsored by an agency of the United States Government. Neither the United States Government nor any agency thereof, nor any of their employees, makes any warranty, express or implied, or assumes any legal liability or responsibility for the accuracy, completeness, or usefulness of any information, apparatus, product or process disclosed, or represents that its use would not infringe privately owned rights. Reference herein to any specific commercial product, process or service by trade name, trademark, manufacturer, or otherwise does not necessarily constitute or imply its endorsement, recommendation, or favoring by the United States Government or any agency thereof. The views and opinions of authors expressed herein do not necessarily state or reflect those of the United States Government or any agency thereof.

This report has been reproduced directly from the best available copy.

Available for sale to the public, in paper, from: U.S. Department of Commerce, National Technical Information Service, 5285 Port Royal Road, Springfield, VA 22161, phone: (800) 553-6847, fax: (703) 605-6900

email: orders@ntis.fedworld.gov

online ordering: http://www.ntis.gov/help/index.asp

Available electronically at http://www.osti.gov/bridge

Available for a processing fee to U.S. Department of Energy and its contractors, in paper, from: U.S. Department of Energy, Office of Scientific and Technical Information, P.O. Box 62, Oak Ridge, TN 37831-0062,

phone: (865)576-8401,

fax: (865)576-5728

email: $\underline{\text { reports@ adonis.osti.gov }}$ 


\section{TABLE OF CONTENTS}

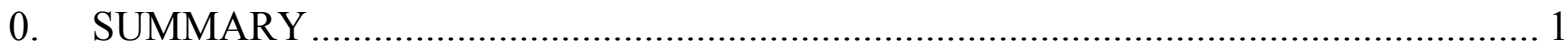

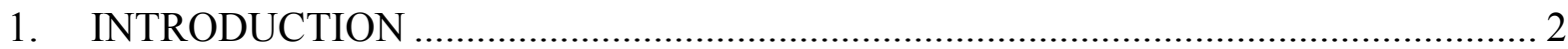

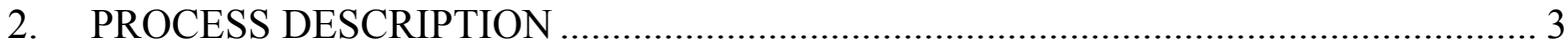

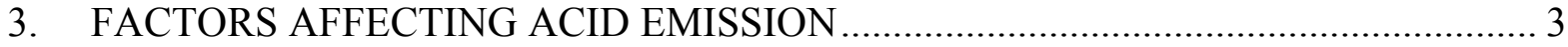

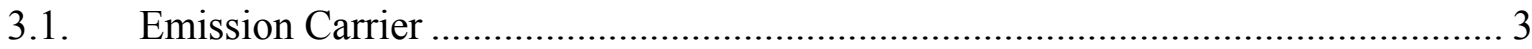

3.2. Emission Sources ...................................................................................... 4

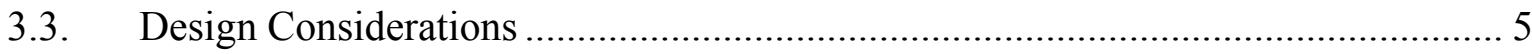

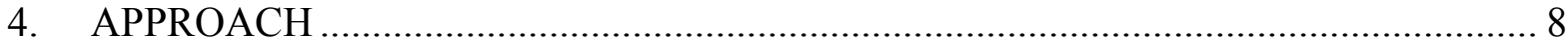

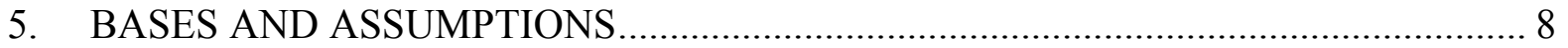

6. CALCULATION ................................................................................................ 9

6.1. Calculation of Maximum Air Flow................................................................ 9

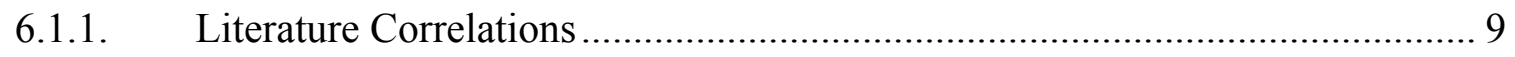

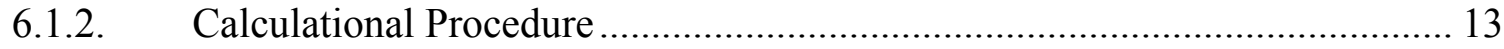

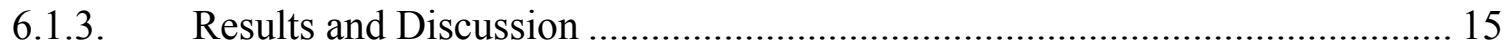

6.2. Calculation of Maximum Air Emission .......................................................... 17

6.3. Staged Model of Scale Formation and Dissolution .......................................... 19

6.3.1. F-Canyon Waste Compositions ................................................................ 19

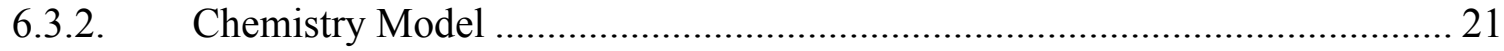

6.3.3. Process Model .......................................................................................... 22

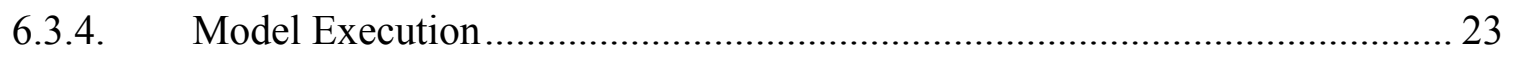

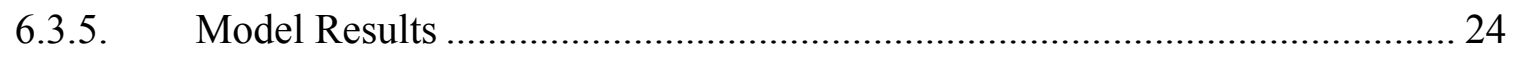

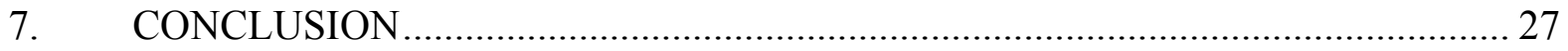

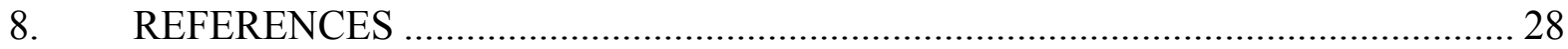

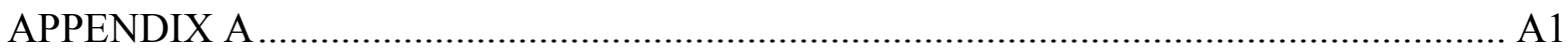

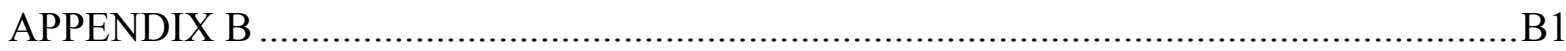




\section{LIST OF FIGURES}

FIGURE 1. Parameters for Pressure Drop in Gas-Liquid Flow through Horizontal Pipes (Taken from Ref. [10]) 11

FIGURE 2. Gas-Liquid Flow Patterns in Horizontal Pipes (Taken from Ref. [10]) .......................... 11

FIGURE 3. Liquid Volume Fraction in Gas-Liquid Flow (Taken from Ref. [10])........................... 11

FIGURE 4. Flow-Pattern Regions in Cocurrent Gas-Liquid Flow Through Horizontal Pipes

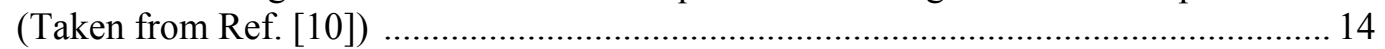

FIGURE 5. Calculated Superficial Phase Velocities vs. L-M Parameter $X$..................................... 16

FIGURE 6. Schematic of Waste Header \#2 Scale Formation and Dissolution Model...................... 22

FIGURE 7. Acid Concentration in Final Spent Acid vs. Waste-to-Acid Feed Ratio .......................... 25

$\underline{\text { FIGURE 8. }}$. Acid Emission and Scaling Tendency vs. Acidity in Final Spent Acid .........................26

\section{LIST OF TABLES}

TABLE 1. List of Engineering Drawings Referenced in This Task ............................................. 7

TABLE 2. Design and Physical Property Data Used in This Study ............................................ 15

TABLE 3. $\quad$ Results of Hydraulic Calculations for Maximum Air Flow ........................................... 16

TABLE 4 Chemical Compositions and Processing Rates of Six F-Canyon Regular Waste Streams ...........................................................20

TABLE 5 Dry-Basis Composition of Composite F-Canyon Regular Waste and Component-by- Component Contributions by Each Waste Stream ................................220

TABLE 6. Species Included in Waste Header \#2 Chemistry Model ............................................. 21

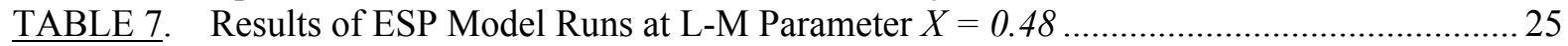




\section{NOMENCLATURE}

A

$A_{p}$

$C_{D}$

$d_{p}$

$D$

$f$

$g$

$h_{L}$

$L$

$m_{p}$

•

$n$

$P$

$Q$

$R$

$R_{L}$

$T$

$u_{t}$

$v$

$V$

$V P$

$X$

$Y$

$z$

\section{Greek Letters}

$\rho$

$\sigma$

$\lambda$

$\varepsilon$

$\mu$

$\psi$

subscripts

$G$
$L$
$T P$

superscripts

G

$L$

$T P$ cross-sectional area of Waste Header \#2, $\mathrm{ft}^{2}$

projected area of particle in direction of motion, $\mathrm{ft}^{2}$

drag coefficient, dimensionless

particle diameter, $\mathrm{ft}$

diameter of Waste Header \#2, $\mathrm{ft}$

friction factor, dimensionless

gravitational acceleration, $\mathrm{ft} / \mathrm{sec}^{2}$

frictional loss of head, $\mathrm{ft}$

length of Waste Header \#2, $\mathrm{ft}$

particle mass, $1 b$

mass flow rate, $\mathrm{lb} / \mathrm{hr}$

molar flow rate, gmole/hr

static pressure, $1 \mathrm{~b} / \mathrm{in}^{2}$

volumetric flow rate, $\mathrm{ft}^{3} / \mathrm{min}$

universal gas constant, atm. $\mathrm{ft}^{3} /$ gmole $/ \mathrm{K}$

liquid volume fraction, dimensionless

absolute temperature, $\mathrm{K}$

terminal velocity, $\mathrm{ft} / \mathrm{sec}$

fluid velocity, $\mathrm{ft} / \mathrm{sec}$

superficial gas velocity in the FPT-3, ft/sec

vapor pressure, $\mathrm{mmHg}$

Lockhart-Martinelli parameter, dimensionless

Lockhart-Martinelli parameter, dimensionless

elevation, $\mathrm{ft}$

fluid weight density, $\mathrm{lb} / \mathrm{ft}^{3}$

surface tension, $\mathrm{N} / \mathrm{m}$

parameter defined by Eq. (14), dimensionless

pipe roughness factor, $\mathrm{ft}$

absolute viscosity, $\mathrm{lb} / \mathrm{ft} / \mathrm{sec}$

parameter defined by Eq. (15), dimensionless

gas-phase

liquid-phase

two-phase

gas-phase

liquid-phase

two-phase 


\section{LIST OF ACRONYMS}

$\begin{array}{ll}\text { CFM } & \text { cubic feed per minute } \\ \text { CSTE } & \text { Concentrate, Storage \& Transfer Engineering } \\ \text { ESP } & \text { Environmental Simulation Program } \\ \text { FCAN-RW } & \text { F-Canyon Regular Waste } \\ \text { FPP-2/3 } & \text { F Tank Farm Pump Pits \#2 and \#3 } \\ \text { FPT-3 } & \text { F Tank Farm Pump Tank \#3 } \\ \text { GP } & \text { General-Purpose } \\ \text { HAW } & \text { High Activity Waste } \\ \text { HLW } & \text { High Level Waste } \\ \text { L-M } & \text { Lockhart and Martinelli } \\ \text { NESHAPS } & \text { National Emission Standards for Hazardous Air Pollutants } \\ \text { PVV } & \text { Process Vessel Vent } \\ \text { T-T } & \text { turbulent-turbulent } \\ \text { T-V } & \text { turbulent-viscous } \\ \text { V-V } & \text { viscous-viscous } \\ \text { VLE } & \text { vapor-liquid equilibrium } \\ \text { WCP } & \text { Waste Compliance Plan }\end{array}$




\section{SUMMARY}

The purpose of this study was to develop the air emission projections for the maintenance operation to dissolve and flush out the scale material inside the F-Canyon Waste Header \#2. The chemical agent used for the dissolution is a concentrated nitric acid solution, so the pollutant of concern is the nitric acid vapor. The results of the scale dissolution chemistry modeling showed that there would be no $\mathrm{NO}_{\mathrm{x}}$ emission during the acid flush. Under the very conservative operating scenarios considered in this study, it was determined that the highest possible rate of nitric acid emission during the acid flush would be $0.048 \mathrm{lb} / \mathrm{hr}$. It turns out that this worst-case air emission projection is just below the current exemption limit of 0.05 $\mathrm{lb} / \mathrm{hr}$ for permit applications.

This study was conducted in the absence of several key pieces of data that are essential to the development of accurate air emission projections. Particularly, no information was available on the approximate quantity, location(s) and chemistry of the scale material deposited in the Waste Header \#2 and the rate and direction of air flow through the header during normal waste transfers. As a result, several assumptions had to be made in this study to ensure that the resulting air emission projections would not only be realistic but also bounding. One such assumption made based on the extensive review of available design drawings and operating data was that the maximum static pressure inside the Building 221-F waste headers would be no higher than the atmospheric pressure.

The assumed maximum waste header pressure on the canyon side along with the measured static pressure of the F Tank Farm Pump Tank \#3 and the known elevation drop across the length of the Waste Header \#2 formed the bases for estimating the maximum air flow through the header using the hydraulic correlations available in the literature. The maximum air flow through the Waste Header \#2 thus estimated was $4.84 \mathrm{cfm}$, which is equivalent to about $5 \%$ of the total air inleakage into the F Tank Farm Pump Tank \#3. The maximum air emission projection of $0.048 \mathrm{lb} / \mathrm{hr}$ was then obtained by fully saturating this air flow with the equilibrium vapor of $50 \mathrm{wt} \%$ nitric acid solution. The resulting air emission projection is very conservative, since it was derived based on the worst-case scenario of ambient air flowing in the direction of the FTP-3 at its maximum possible rate and becoming fully equilibrated with the fresh nitric acid solution flowing through the deposit-free waste header. It is, therefore, concluded that there is no realistic probability that the nitric acid emission at the stack of the FPP-2/3 ventilation system would ever exceed the current exemption limit of $0.05 \mathrm{lb} / \mathrm{hr}$.

A process model of scale formation and subsequent acid dissolution was also developed in this study using the Environmental Simulation Program (ESP) version 6.6 and run with the compositional data given in the Waste Compliance Plan for the six F-Canyon regular waste types. The simulation results showed that the scale material was indeed mostly made up of ferric hydroxide, and some of the uranium in the High-Activity Waste and General-Purpose evaporator concentrates was also predicted to precipitate out as sodium diuranate. The modeling results also confirmed one of the key bases of the hydraulic calculations that the maximum acid emission would occur when the fresh acid is flowing through the deposit-free waste header concurrently with ambient air. 


\section{INTRODUCTION}

The liquid waste generated in the F-Canyon during the separation and recovery of $\mathrm{Pu}-239$, $\mathrm{Np}-237$, and U-238 from irradiated uranium targets and fuel rods is transferred out of Building 221-F to the F-Area Tank Farm via one of the four waste headers. Lately, the Waste Header \#2 that connects to the F Tank Farm Pump Tank \#3 (FPT-3) has been experiencing pluggage at increasing frequency, thus requiring a periodic cleanup for its continued operability. The exact chemistry of the scale material is not known, since no samples have been collected and analyzed thus far. From the Canyon's operating history, however, it has been postulated that the plugging is caused mainly by the slow buildup of ferric hydroxide precipitates, and the increased frequency of plugging is likely due to increased usage of ferrous sulfamate since October 1999 to neutralize the sump solution. ${ }^{1}$

A concentrated nitric acid solution at $50 \%$ by weight has been used effectively to dissolve the scale material plugging the Waste Header \#2. Prior to the addition of 9,000 pounds of 50 $\mathrm{wt} \%$ nitric acid solution, 16,500 pounds of $30 \mathrm{wt} \% \mathrm{NaOH}$ solution will be added to the FPT3 on top of the 1,400 gallons of caustic heel already present in the tank in order to neutralize the spent acid solution. A Waste Compliance Plan (WCP) has been prepared that describes these acid cleaning steps in detail.

One issue not addressed in the WCP is the projected release of nitric acid vapor to the surrounding atmosphere and the potential personnel exposure. The vapor pressure of aqueous solutions of nitric acid is a strong function of both temperature and $\mathrm{pH}$, and the acid cleanup process involves handling of concentrated nitric acid solutions. As a result, a concern has been raised that the instantaneous emission rate of nitric acid vapor could exceed the current exemption limit of $0.05 \mathrm{lb} / \mathrm{hr}$ set for the permitting applications.

To address this emission concern, a technical task request was issued by the Concentrate, Storage \& Transfer Engineering (CSTE) that requires the SRTC personnel to develop the instantaneous air emission projections during the acid flushing of plugged waste headers. ${ }^{2}$ The focus of this study was on the Waste Header \#2, F-Canyon's only operational waste header, and the estimation of a bounding air emission of nitric acid through the FPP-2/3 ventilation system during the cleaning operation. This report summarizes all the key bases and assumptions made in the analysis along with the results of hydraulic calculations and the ESP modeling. The predicted equilibrium speciation of all the chemical constituents of the scale material and its counterparts dissolved in the spent acid solution is given in the steady state material balance table attached at the end of this report. 


\section{PROCESS DESCRIPTION}

The WCP lists the following operational steps for the acid flush of the F-Canyon Waste Header \#2: ${ }^{1}$

i. Transfer 16,500 pounds (lbs) of $30 \mathrm{wt} \% \mathrm{NaOH}$ through Waste Header \#1 to FPT-3. This 1,490 gallons of $30 \mathrm{wt} \% \mathrm{NaOH}$ (based on the density of $1.3277 \mathrm{~g} / \mathrm{ml}$ at $20{ }^{\circ} \mathrm{C}$ ) along with 1,400 gallons of caustic heel already present in the FPT-3 will make up the total caustic inventory available for the neutralization of spent acid solution.

ii. Flush Waste Header \#1 using 2,000 lbs of water. Spent flush will flow into the FPT-3.

iii. Transfer 9,000 lbs of $50 \mathrm{wt} \%$ nitric acid through Waste Header \#2 to FPT-3. Based on the density of $1.31 \mathrm{~g} / \mathrm{ml}$ at $20{ }^{\circ} \mathrm{C}$, this is equivalent to 823 gallons of acid, which is enough to fill $93 \%$ of the entire volume of Waste Header \#2. Depending on the severity of pluggage, it would take 2 to 4 hours to complete this step, ${ }^{3}$ during which practically all of the projected acid emission would occur.

iv. Flush Waste Header \#2 using 2,000 lbs of water. Any residual acid and loose scale material remaining in the waste header will be flushed, and the spent flush will flow into the FPT-3.

Obviously, there will be no acid emission during Steps (i) and (ii). In Step (iv), the emission due to residual acid will be insignificant due to dilution with flush water. It is also noted that the moles of hydroxide ions added in Step (i) equals $175 \%$ of the moles of acids added in Step (iii). Therefore, even without the 1,400-gallon caustic heel, there will be more than enough hydroxides present initially in the FPT- 3 to neutralize all the fresh acids added before they are consumed by the dissolving scale material.

\section{FACTORS AFFECTING ACID EMISSION}

In this section, various sources for acid emission during the Waste Header \#2 cleaning are identified and the worst-case scenario for the maximum acid emission is discussed briefly from the design, operational, and thermodynamic aspects of the cleaning process.

\subsection{Emission Carrier}

Without a carrier gas, there would be no air emission except due to displacements. For the FPT-2 and FPT-3, there is no carrier gas in the form of dedicated air purges. However, there is a leakage of ambient air into the pump pit cells and then into the pump tanks, since the FPP-2/3 ventilation system is pulling a slight vacuum on each tank and on the pump pit cells enclosing the tanks. The volumetric flow rate of this air inleakage was measured to be $193 \mathrm{cfm}$ (or $171 \mathrm{scfm}$ ) at the stack of the FPP-2/3 ventilation system during a recent NESHAPS test. ${ }^{4}$ Since both FPT-2 and FPT-3 are identical in design, it seems logical to assume that both tanks contribute equally to the measured total air flow. The air inleakage to the FPT-3 only is then $96.5 \mathrm{cfm}$. 
Available drawings of the FPT-3 show a number of jumper connections off the top and two off the sidewalls, each contributing to the total air inleakage to the tank. But the Waste Header \#2 is the only transfer line containing the acid for any length of time. The question is then what fraction of the FPT-3 air inleakage would come in through the Waste Header \#2 as the carrier for acid emission, if indeed there were an air flow through the header in the direction of FPT-3.

Once inside the FPT-3, much of the air inleakage is likely to flow straight to the exit port located near the center of the crown, bypassing much of the vapor space. Nevertheless, a small portion of the air inleakage would inevitably come in contact with the liquid in the tank and may pick up an additional acid emission before exiting the tank. However, even if the entire air inleakage were to equilibrate with the dissolved acid, the likelihood of any significant acid emission due to the vapor-liquid contact in the tank would be minimal for the following reasons. First, the caustic level in the tank at the start of acid cleaning is $\sim 100 \%$ in excess of the stoichiometric amount required to neutralize all the fresh acid added prior to any dissolution of scale material. Second, the contents of FPT-3 will be agitated continuously throughout the acid cleaning. ${ }^{5}$ Third, the kinetics of the acid-base neutralization reaction is fast compared to the average gas residence time of 34 seconds in the FPT-3, which was estimated based on the total air flow of $96.5 \mathrm{cfm}$ at $35{ }^{\circ} \mathrm{C}$. Therefore, the concentration of residual acid in the liquid should fall close to zero in the given time frame and contribute little to the total acid emission.

\subsection{Emission Sources}

The nitric acid can get airborne by two distinct mechanisms. First, nitric acid mists can get entrained by the gas stream if the local gas velocity is sufficiently high, and the mist sizes are sufficiently small. A likely scenario for this physical entrainment is when the spent acid solution exits the Waste Header \#2 and free falls onto the contents of FPT-3. In order to check the feasibility of this scenario, the superficial gas velocity in the 12-ft diameter FPT-3 vapor space was first calculated to be $0.142 \mathrm{ft} / \mathrm{sec}$ based on the total air flow of 96.5 -cfm estimated above. Then, the size of mist droplets whose terminal velocity would equal this superficial gas velocity was next calculated to be $35 \mu \mathrm{m}$ by iteratively solving the literature correlation (see Sample Calculation \#1 in Appendix). It means that the spent acid solution will not be entrained into the ventilation system, unless the droplet sizes become smaller than $35 \mu \mathrm{m}$. Without the use of an atomizer, it is unlikely that such fine droplets would be produced in any significant quantities from a liquid stream free falling only $\sim 3 \mathrm{ft}$. As a result, the acid emission due to physical entrainment was deemed insignificant and no longer considered in this study.

In the absence of physical entrainment, the emission of nitric acid vapor from an aqueous solution is determined entirely by the following phase equilibrium between the dissolved but undissociated acid and its vapor phase counterpart at the system temperature and pressure:

$$
\mathrm{HNO}_{3}(\mathrm{aq}) \leftrightarrow \mathrm{HNO}_{3}(\mathrm{~g})
$$


The undissociated nitric acid molecule is further in equilibrium with its constitutive ions in the liquid phase:

$$
\mathrm{HNO}_{3}(\mathrm{aq}) \leftrightarrow \mathrm{H}^{+}+\mathrm{NO}_{3}^{-}
$$

As the concentration of hydronium ion $\left(\mathrm{H}^{+}\right)$is increased, i.e., with decreasing $\mathrm{pH}$, the equilibrium balance of Reaction (2) will shift to the left, resulting in a higher concentration of undissociated nitric acid and thus a higher emission of nitric acid vapor. In a multi-electrolyte solution, the equilibrium balance of Reaction (2) is further influenced by the presence of other dissolved species, and their impact is typically measured in terms of ionic strength of a solution. ${ }^{4}$ For example, when the ferric hydroxide precipitates are dissolved by reacting with free acid via Reaction (3), this will push the equilibrium balance of Reaction (2) to the right, resulting in a lower concentration of undissociated acid and thus a lower emission of nitric acid vapor:

$$
\mathrm{Fe}(\mathrm{OH})_{3}(s)+3 \mathrm{H}^{+} \rightarrow \mathrm{Fe}^{+3}+3 \mathrm{H}_{2} \mathrm{O}
$$

Thus, the maximum acid emission would occur when the acidity of the liquid phase and the air flow through the Waste Header \#2 are both at their highest. Clearly, the highest possible acidity for the liquid phase is that of the fresh acid, and this would occur only after all the scale material initially present is dissolved. It means that the quantity of acid added must be in excess of what is required stoichiometrically by Reaction (3) to ensure that there is a surplus of $50 \mathrm{wt} \%$ nitric acid flowing through the deposit-free header. Unfortunately, there is no way to confirm the sufficiency of acid addition when there exist no data on the quantity of scale material deposited. Nevertheless, the air emission projections will be developed in this task based on the excess acid addition scenario.

Likewise, the maximum air flow inside the Waste Header \#2 cannot be determined uniquely either due to a lack of data. Obviously, there will be no air flowing inside the header if it is completely plugged prior to the initiation of acid addition; the air will only begin flow when the scale material finally begins dissolve away sometime after the initiation of acid addition. It is, however, unknown in which direction the air will flow, since both ends of the header are being pulled by separate ventilation systems, and the static pressures are never measured in the canyon waste headers. It is therefore necessary to make some realistic but conservative assumptions about this critical air flow and, before making such assumptions, some of the key design features of the FCanyon and FPT-3 ventilation systems are reviewed next.

\subsection{Design Considerations}

There are four 10-inch waste headers in the F-Canyon that run along the length of Building 221-F for more than $800 \mathrm{ft}$. These headers are slightly $(0.5 \%)$ sloped so that the liquid wastes transferred into these headers will flow by gravity from north to south. At the south end of the building (Section 4), the diameter of each waste header is reduced from 10 to 3 inches in the Transition Box, and the four waste headers of 
reduced diameter are split into two pairs, before exiting the canyon building. For the containment of any potential leakage, each pair of 3-inch waste header pipes are encased in a 10-inch outer pipe for the entire transfer length from the Transition Box to the F-Area Pump Pits (FPP).

The Waste Header \#2 is contained in one of the two 10-inch outer pipes, and the waste transfer over its entire length of 2,311 ft to FPT-3 is induced by gravity due to a total elevation drop of $43 \mathrm{ft}$. According to the design drawings, the Waste Header \#2 has a total of 27 elbows or bends; at "change of slope" bends, the 10-inch outer jackets are mitered, and the core pipes are bent at a 5-inch radius. It appears from the drawings that most of the long, straight sections of the waste header are sloped only slightly $(\sim 0.5 \%)$, so there exists a definite potential for the settlement and accumulation of undissolved waste particles in these leveled locations.

In order to determine the maximum possible air flow through the Waste Header \#2 and its direction, the static pressures must be known at both ends. According to the F-Area Pump Pit (FPP) operator roundsheets, the static pressure in the FPT-3 vapor space ranged from -1.7 to -1.8 inches of water column ("wc) during October 2002, which probably represents a good historical average. ${ }^{6}$ On the other hand, the static pressures inside the F-Canyon's waste headers are never measured; the only static pressure data available for this study was -25 "wc measured at the inlet of the Process Vessel Vent (PVV) fan. ${ }^{7}$ The next logical step was then to find out whether the waste header pressures could be back calculated from this measured data by reviewing the overall piping configuration from the waste headers to the PVV fan.

At the north end of Building 221-F (Section 18), the elevation of each 10-inch waste header is abruptly raised by 5 feet near its sealed end, and each waste header is vented through a 3-inch pipe from these raised ends. The four 3-inch vent pipes are then merged into a single 4-inch vent pipe, which is in turn connected to the 18 -inch PVV header further downstream. Unfortunately, the only PVV system drawing available to this study (Drawing \#W148392) did not contain necessary data for a rough estimation of the waste header pressures. Besides, with so many tanks vented to the waste and PVV headers, any attempt to develop a detailed hydraulic model of the canyon's ventilation system would have been clearly beyond the scope of this task, even if all the necessary drawings had been made available.

Nevertheless, considering the fact that there are no major flow resistances between the waste headers and the PVV fan (e.g., filters and heaters), it is very likely that the static pressures inside the waste headers, especially in the Transition Box, would still be significantly negative. In other words, the canyon's ventilation system could easily overpower that of the FPP-2/3 so that the static pressure on the canyon side could be low enough to overcome the elevation head difference of $43 \mathrm{ft}$ across the entire length of Waste Header \#2. If so, the air inside the Waste Header \#2 will then flow in the direction of the F-Canyon and, in this case, the emission of nitric acid vapor through the FPP-2/3 ventilation system will be negligible. It is noted that the same cannot be said for the liquid flows, since the elevation head difference cannot be easily overcome due to their much higher densities. 
In this study, however, it will be assumed that once the pluggages are removed, the air will flow in the opposite direction, i.e., from the F-Canyon to the FPT-3 in an effort to develop conservative air emission projections. To support this assumption, the static pressure on the canyon end of the Waste Header \#2 must be higher than that on the FPT-3 end minus the elevation head difference of $43 \mathrm{ft}$. If the measured FPT-3 static pressures are rounded to -2 "wc (which will result in a higher air flow in the direction of FPT-3), the minimum canyon static pressure must then be greater than -2.6 "wc, assuming a single-phase flow, in order to maintain the specified air flow direction (see Sample Calculation \#2 in Appendix).

Once the direction of air flow in the Waste Header \#2 is set, its rate will then depend on how high the actual canyon static pressures are above the minimum value. As stated above, with the PVV fan running continuously to maintain a constant suction pressure of -25 "wc, the static pressures in the canyon waste headers are expected to be much lower than -2.6 "wc. In fact, the canyon PVV and exhaust systems were designed to maintain a relative vacuum in all the vessels and headers with respect to the canyon cell, which in itself is under vacuum. Therefore, it should be sufficiently conservative from the acid emission standpoint to assume that the maximum static pressure in the canyon waste headers is not higher than the atmospheric pressure.

Additional conservatism was added to the analysis by ignoring reduced emission by way of off-gas abatement. The actual emission of nitric acid at the stack will be less than that exiting the FPT-3 vapor space, since much of the nitric acid vapor will be scrubbed out in the FPP-2/3 ventilation system, which consists of a de-mister, a twopass condenser, a pre-heater, and a HEPA filter. As a conservative measure, however, no credit will be taken in this study for any removal of acid vapor in the ventilation system.

Much of the key design data for the waste headers and the ventilation systems of Building 221-F and the FPP-2/3 were obtained from the following engineering drawings listed in Table 1, which can be accessed either through Document Control or downloaded from http://drawings.srs.gov/cgi-bin/docid2.

TABLE 1. List of Engineering Drawings Referenced in This Task.

\begin{tabular}{|l|l|}
\hline Drawing No. & Title \\
\hline W148392 & 200 Area, Plans and Sections, Canyon Exhaust Air Duct Process Vent Header \\
\hline W164285 & BLDG 221F Process Header Piping Diagram Sheet No. 5 Pump out and Waste \\
\hline W715434 & BLDG 241F, Transition Box Sections \& Details Process \& Inst. \\
\hline W713074 & BLDG 241F, WF 221F - Catch Tank, Piping Arrangement SH2 \\
\hline W713075 & BLDG 241F, WF 221F - Catch Tank, Piping Arrangement SH3 \\
\hline W713076 & BLDG 241F, WF 100 \& WF 102 - FPP \#2 \& \#3, Piping Arrangement Elev \\
\hline W703333 & BLDG 241F, WF Line-FDV1 to FPP \#2 \& \#3 @FDV4, Piping ARRGT. Elev \\
\hline W701552 & BLDG 241F, WF DB1 to Pump Pit 3 Piping Arrgt. Plan \\
\hline W700658 & BLDG 241F, PP 2 \& 3 \& DB4 Equip. Arrg’t SH1 \\
\hline W703322 & BLDG 241F, WF Line - FDB1 to P.P. 2\&3 Piping Arrgt. Plan \\
\hline W701538 & High Level Waste Storage, P. P. 2 \& 3; D.B.4, H \& V (U) \\
\hline MM6F3119 & F Area Pump Pit 3 Waste Transfer System, Piping and Instrument Drawing \\
\hline BPF212512 & Pump Tank \\
\hline
\end{tabular}




\section{APPROACH}

With the significant emission sources identified and the carrier gas flows set, the overall approach taken to develop conservative nitric acid emission projections consisted of the following steps:

A. Determine the maximum possible air flow through the Waste Header \#2 using the hydraulic correlations available in the literature for single- and two-phase flows.

B. Estimate the maximum air emission of nitric acid by saturating the maximum air flow calculated in Step (A) at the vapor pressure of $50 \mathrm{wt} \%$ nitric acid.

C. Build a staged process model of scale formation and subsequent acid dissolution using the ESP software.

D. Develop the chemical composition of the composite waste consisting of the six FCanyon regular waste types.

E. Run the ESP model at different waste-to-acid mass ratios in order to confirm that the acid emission projection derived in Step (B) represents the worst-case.

In essence, this report is a summary of results and conclusions from each of these five steps. All the key equations and/or correlations used are given in the CALCULATION section along with a brief description of each calculational method used. The detailed calculations are given in Sample Calculations \#3 in Appendix.

\section{BASES AND ASSUMPTIONS}

The following bases and assumptions were employed in the development and subsequent confirmation of conservative air emission projections during the acid cleaning:

1. The maximum static pressure inside the F-Canyon's waste headers is 0 "wc vacuum or 14.696 psia.

2. The average static pressure in the FPT-3 vapor space is -2 "wc.

3. The Waste Header \#2 is a straight pipe with no bends or elbows.

4. The carryover of nitric acid aerosols due to physical entrainment is negligible.

5. The instantaneous concentration of undissociated nitric acid in the liquid phase of FPT-3 is negligibly small throughout the acid cleaning period.

6. Any scrubbing of nitric acid vapor in the FPP-2/3 ventilation system is ignored. 
7. All vapor-liquid equilibria are assumed to occur at $35^{\circ} \mathrm{C}$, which is the measured gas temperature at the stack of the FPP-2/3 ventilation system. ${ }^{4}$ This assumption is conservative from the air emission standpoint, since the acid flush is basically a cold chemical made in the canyon and so should be at around room temperature.

\section{CALCULATiON}

The analyses performed in each of the five steps outlined in the APPROACH section are presented next along with the discussions on some of the key results. Unless otherwise noted, all the units used in this task are the same as those used in Crane. ${ }^{8}$

\subsection{Calculation of Maximum Air Flow}

The air flow through the Waste Header \#2 will be at its maximum when the static pressure difference across the header is at its maximum, and the flow path contains the least number of resistances. By Assumptions \#1 and \#2, the static pressure difference is conservatively set at 2 "wc and, by Assumption \#3, the Waste Header \#2 is treated as a straight 3" Schedule 40S pipe that is 2,311-ft long, thereby ignoring all 27 bends or elbows counted from the design drawings. Since the overall elevation drop is only $43 \mathrm{ft}$ over its entire 2,311-ft length, the mean slope of the header is simply then: $\tan ^{-}$ ${ }^{l}(43 / 2,311)=1.07^{\circ}$. Therefore, the Waste Header \#2 is essentially a horizontal pipe, and any hydraulic correlations derived for horizontal pipes should be applicable.

As discussed earlier, once the air flow is set at its maximum, the acid concentration in the liquid phase must also be at its maximum in order to have the maximum acid emission. The maximum possible concentration of acid in the cleaning solution is clearly that of the fresh acid. Since the acid concentration in the cleaning solution will only decrease as the scale material is dissolved, the maximum acid emission would occur when the fresh acid is flowing through the deposit-free header. Therefore, the flow system to consider for the maximum acid emission is simply a cocurrent gasliquid flow in a straight pipe with a minimal slope.

\subsubsection{Literature Correlations}

The maximum air flow under the two-phase flow pressure drop of 2 "wc and the given elevation drop of 43 feet was calculated using a combination of Darcy's formula, Bernoulli equation, and the semi-empirical correlation by Lockhart and Martinelli (L-M). ${ }^{8,9}$ In essence, the L-M correlation approximates the two-phase pressure drop as the single-phase pressure drop for either phase multiplied by a factor that is a function of the single-phase pressure drops of both phases: ${ }^{10}$

$$
\begin{aligned}
& \left(\frac{\Delta P}{L}\right)_{T P}=Y_{L}\left(\frac{\Delta P}{L}\right)_{L} \\
& \left(\frac{\Delta P}{L}\right)_{T P}=Y_{G}\left(\frac{\Delta P}{L}\right)_{G}
\end{aligned}
$$


where $\mathrm{L}$ is the length of a pipe in feet, and subscripts TP, L and G represent twophase, liquid-phase and gas-phase, respectively. The single-phase pressure drops are calculated as if either the gas or liquid were the only fluid flowing through the entire cross-section of the pipe. The coefficients $\mathrm{Y}_{\mathrm{L}}$ and $\mathrm{Y}_{\mathrm{G}}$ are functions of the L$\mathrm{M}$ parameter, $\mathrm{X}$, which is defined as the ratio of single-phase pressure drops raised to the $1 / 2$ power:

$$
X=\left[\frac{(\Delta P / L)_{L}}{(\Delta P / L)_{G}}\right]^{1 / 2}
$$

By equating Eqs. (4) and (5), it can be shown that $\mathrm{Y}_{\mathrm{L}}$ and $\mathrm{Y}_{\mathrm{G}}$ are related by:

$$
Y_{G}=X^{2} Y_{L}
$$

The L-M correlation is valid for fully developed, incompressible horizontal gasliquid flows. A typical application of the L-M correlation begins by estimating the single-phase pressure drops from the given mass rates of gas and liquid flows using the Darcy's formula for horizontal flows with no appreciable velocity changes:

$$
\frac{\Delta P}{L}=\left(\frac{f \rho}{144 D}\right)\left(\frac{v^{2}}{2 g}\right)
$$

where $f$ is the friction factor, $\rho$ the fluid density in $\mathrm{lb} / \mathrm{ft}^{3}, D$ the pipe diameter in $\mathrm{ft}, v$ the superficial fluid velocity in $\mathrm{ft} / \mathrm{sec}$, and $g$ the gravitational acceleration in $\mathrm{ft} / \mathrm{sec}^{2}$. Once the single-phase pressure drops have been estimated, the L-M parameter, $X$, is next calculated using Eq. (6), and the values of $Y_{L}$ and $Y_{G}$ are read from Figure 1 at the calculated value of $X$. The two-phase pressure drop is then calculated using either Eq. (4) or (5).

Figure 2 shows seven flow patterns that could develop in horizontal gas-liquid flow. Bubble flow occurs at high liquid-to-gas mass flow ratios and gradually transitions to plug, stratified, wavy, slug, annular, and spray flow as the liquid-to-gas flow ratio continues to decrease. The pressure drop predictions based on the L-M correlation are in general known to be high for stratified, wavy, and slug flows and low for annular flow [10]. Therefore, in order to preserve the validity of applying the L-M correlation to this problem, it is necessary to ensure that the predicted two-phase flow in the Waste Header \#2 is either bubble or plug flow. In bubble flow, the gas is dispersed as bubbles near the top of the pipe, while in plug flow alternate plugs of gas and liquid move along the upper part of the pipe. In either flow, the difference between in-situ velocities of the gas and liquid phases is small.

Since the mass rates of gas and liquid flows constitute the unknowns in this study, the calculational procedure described above for a typical application of the L-M correlation should in principle be applied in the reverse order. However, one unique feature of this inverse application of the L-M correlation is that there will likely be several different combinations of gas and liquid flows that would give rise to the 
same two-phase pressure drop. In other words, a range of gas flows (and the corresponding range of liquid flows) would result from a given two-phase pressure drop. However, before deciding on the upper-bound gas velocity for the maximum air emission purpose, it would be necessary first to filter these multiple solutions by checking if a particular set of gas and liquid flows would result in a desired twophase flow pattern, i.e., bubble or plug flow.

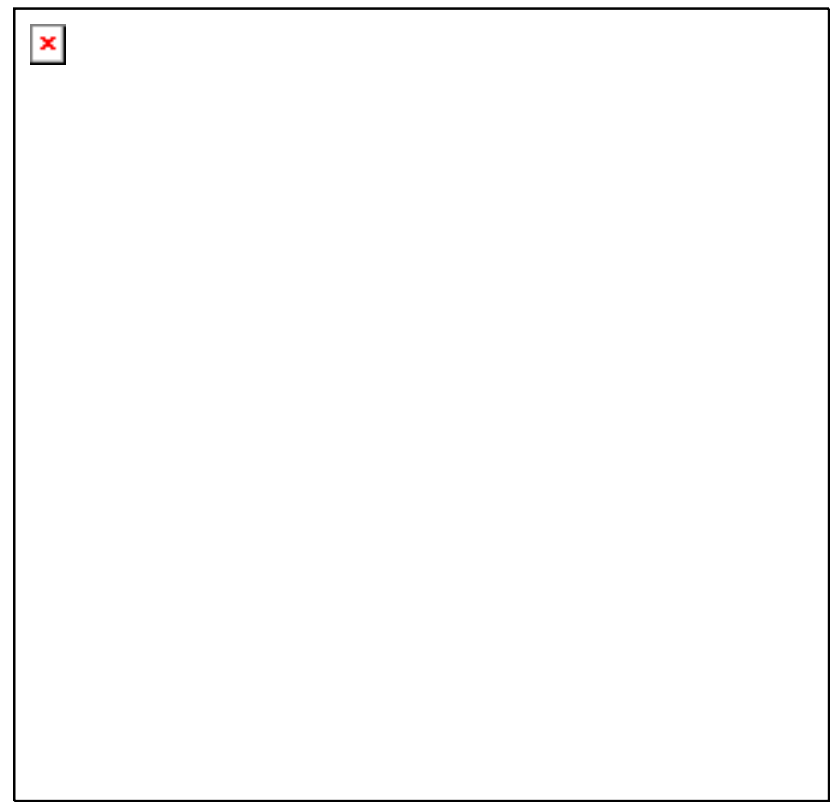

FIGURE 1. Parameters for Pressure Drop in Gas-Liquid Flow through Horizontal Pipes (Taken from Ref. [10]).
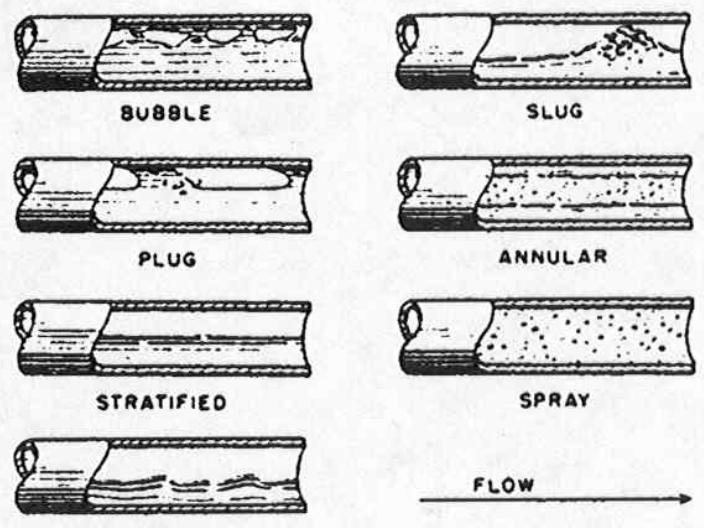

FLOW

WAVY

FIGURE 2. Gas-Liquid Flow Patterns in Horizontal Pipes (Taken from Ref. [10]). 
Although it is well justified to assume that the Waste Header \#2 is a horizontal pipe, the overall elevation head difference of $43 \mathrm{ft}$ across its length is still significant especially in light of the very small static pressure difference of only 2 "wc. Eqs. (4) and (5) can then be reformulated into a more general form by replacing the pressure differential terms with the total head loss using the Bernoulli equation:

$$
h_{L}=z_{1}-z_{2}+\frac{144}{\rho}\left(P_{1}-P_{2}\right)
$$

where $h_{L}$ is the total head loss in feet of fluid, $z$ the elevation head in feet, $\rho$ the weight density of fluid in pounds per cubic feet and $P$ the pressure in pounds per square inch. Subscripts 1 and 2 refer to the F-Canyon and FPT-3 ends of the Waste Header \#2, respectively. In Eq. (9), both the fluid density and velocity are assumed to remain unchanged due to the small static pressure difference. The revised L-M correlation used in this study is then:

$$
\begin{aligned}
& \left(\frac{h_{L}}{L}\right)_{T P}=Y_{L}\left(\frac{h_{L}}{L}\right)_{L} \\
& \left(\frac{h_{L}}{L}\right)_{T P}=Y_{G}\left(\frac{h_{L}}{L}\right)_{G}
\end{aligned}
$$

where the subscripts $T P, L$ and $G$ represent the two-phase, liquid, and gas phases, respectively. Again, the substitution of $\Delta P$ 's in the original L-M correlation with $h_{L}$ 's was possible due to the fact that the mean inclination angle of the Waste Header \#2 is only $-1^{\circ}$ from the horizontal plane.

Limiting the allowable flow pattern to either bubble or plug flow further allows us to treat the two-phase flow inside the Waste Header \#2 as a homogeneous mixture, which subsequently permits the application of Eq. (9) for the calculation of the total head loss of a two-phase flow. To do that, the volume fraction of each phase must be known so that the mixture density in Eq. (9) could be estimated. Another L-M correlation shown in Figure 3 was used to estimate the liquid volume fraction, $R_{L}$, in gas-liquid flow through horizontal pipes.

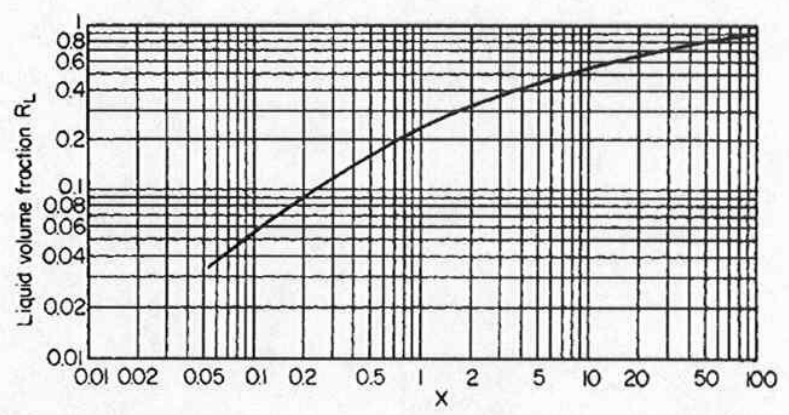

FIGURE 3. Liquid Volume Fraction in Gas-Liquid Flow (Taken from Ref. [10]). 


\subsubsection{Calculational Procedure}

The overall procedure taken for the inverse application of the L-M correlation was as follows:

1. Assume $X$.

2. $\operatorname{Read} R_{L}$ from Figure 3 .

3. Calculate the mixture density as: ${ }^{12}$

$$
\rho_{T P}=\rho_{L} R_{L}+\rho_{G}\left(1-R_{L}\right)
$$

where the subscripts $L$ and $G$ refer to the liquid (50 wt $\%$ nitric acid) and gas (air) phases, respectively.

4. Calculate the total head loss of the two-phase flow, $h_{L}^{T P}$, at $\Delta z=43 \mathrm{ft}$ and $\Delta P$ $=0.072$ psi, using Eq. (9).

5. Assume a flow regime for each phase, i.e., turbulent (T) or viscous (V).

6. Read either $Y_{G}$ or $Y_{L}$ from Figure 1 at the assumed value of $X$ and gas-liquid flow regimes, i.e., T-T, T-V or $\mathrm{V}-\mathrm{V}$. Estimate the value of the other parameter using Eq. (7).

7. Calculate the total head loss of each single-phase flow, $h_{L}^{G}$ and $h_{L}^{L}$, using Eqs. (10) and (11).

8. Estimate the superficial velocity of each phase using the Darcy's formula rearranged as follows:

$$
v=\sqrt{\frac{2 g h_{L} D}{f L}}
$$

where $h_{L}$ is the total head loss of each single-phase flow calculated in Step 7. Eq. (13) must be solved iteratively for both $f$ and $v$, since the friction factor, $f$, is a function of Reynolds number, defined as $R e=\rho v D / \mu$, and the pipe roughness factor, $\varepsilon / D$, where $\mu$ is the absolute viscosity of each phase in $\mathrm{lb} / \mathrm{ft} / \mathrm{sec}$ and $\varepsilon$ the absolute roughness in $\mathrm{ft}$.

9. Confirm the gas-liquid flow regimes assumed in Step 5 are correct. If not, assume a different combination of gas-liquid flow regimes and repeat Steps 6 through 9. 
10. Using Figure 4, determine if the gas and liquid flows from Steps would form either bubble or plug flow.

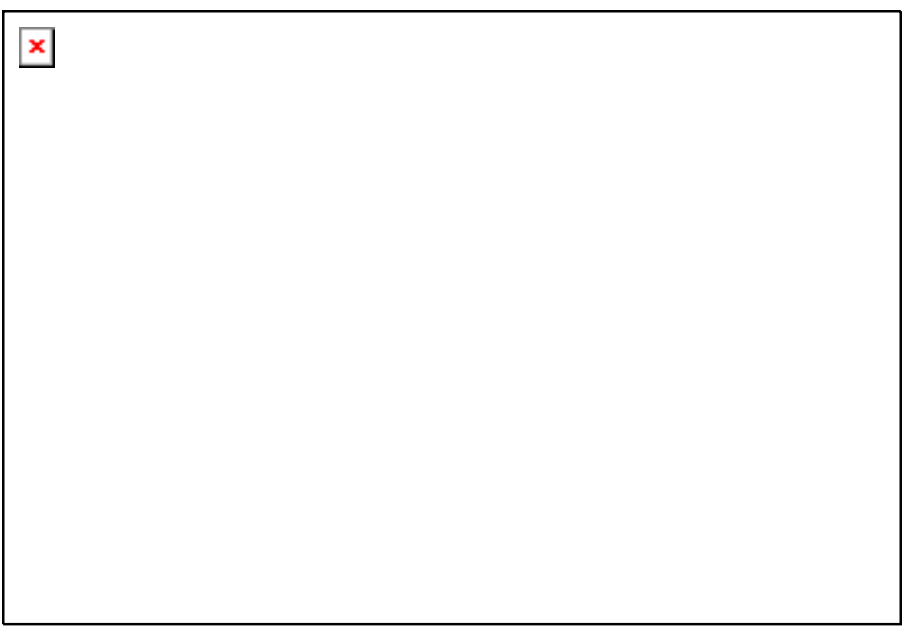

\section{FIGURE 4. Flow-Pattern Regions in Cocurrent Gas-Liquid Flow Through Horizontal Pipes (Taken from Ref. [10]).}

In Figure $4, G_{G}$ and $G_{L}$ are the gas and liquid mass fluxes in $\mathrm{lb} / \mathrm{ft}^{2} / \mathrm{sec}$, respectively, and $\lambda$ and $\psi$ are defined as follows: ${ }^{10}$

$$
\begin{aligned}
\lambda & =\left(\rho_{G}^{\prime} \rho_{L}^{\prime}\right)^{1 / 2} \\
\psi & =\frac{1}{\sigma^{\prime}}\left[\frac{\mu_{L}^{\prime}}{\left(\rho_{L}^{\prime}\right)^{2}}\right]^{1 / 3}
\end{aligned}
$$

where $\rho_{G}^{\prime}$ is the ratio of gas density to air density, $\rho_{L}^{\prime}$ the ratio of liquid density to water density, $\sigma^{\prime}$ the ratio of liquid surface tension to water surface tension, and $\mu_{L}^{\prime}$ the ratio of liquid viscosity to water viscosity. The reference properties are at $68{ }^{\circ} \mathrm{F}$ and atmospheric pressure.

Perhaps, the most critical step in the overall calculational procedure outlined above is the determination of the values of $Y_{G}$ and $Y_{L}$ in Step 6. As shown in Figure 1, the values of $Y_{G}$ and $Y_{L}$ vary considerably for $X<20$ depending on the flow regime chosen for each phase. The transition from viscous to turbulent flow regime takes place at Reynolds numbers between 1,000 and 2,000 for single-phase flows. Since the hydraulic diameter for flow is reduced by the introduction of a second phase, the first phase in the resulting two-phase flow may well be turbulent even for $R_{s p}<$ 2,000 , where the subscript $s p$ stands for single-phase. ${ }^{9}$ Therefore, the criterion of $R e_{s p}=2,000$ for turbulence used in this study is conservative. 


\subsubsection{Results and Discussion}

The maximum air flow through the Waste Header \#2 during the acid cleaning was calculated using the design and physical property data given in Table 2. A total of 8 different cases were considered following the calculational steps outlined in the preceding section (see Sample Calculation \#3 in Appendix for detailed calculations). The calculated values of the key L-M and hydraulic parameters are summarized in Table 3 for $X$ ranging from 0.1 to 1 . The calculated superficial velocities are also plotted in Figure 5 against the L-M parameter, $X$.

TABLE 2. Design and Physical Property Data Used in This Study.

\begin{tabular}{|c|c|c|}
\hline Parameter & Data & Source \\
\hline \multicolumn{3}{|l|}{ Waste Header \#2 (3" Schedule 40S) } \\
\hline - Length, $L$ & $2,311 \mathrm{ft}$ & Ref. 6 \\
\hline - Inner diameter, $D$ & $0.2557 \mathrm{ft}$ & W701552 \\
\hline - Cross-sectional area, $A$ & $0.0513 \mathrm{ft}^{2}$ & “ \\
\hline - Elevation head difference, $z_{1}-z_{2}$ & $43 \mathrm{ft}$ & W715434 \& W703333 \\
\hline - Static pressure on the F-Canyon side, $P_{l}$ & $14.696 \mathrm{lb} / \mathrm{in}^{2}$ & Assumption \#1 \\
\hline - Static pressure on the FPT- 3 side, $P_{2}$ & $14.624 \mathrm{lb} / \mathrm{in}^{2}$ & Ref. 6 \\
\hline \multicolumn{3}{|l|}{ F Tank Farm Pump Tank \#3 (FPT-3) } \\
\hline - Inner diameter, $D_{F P T-3}$ & $12 \mathrm{ft}$ & BPF 212512 \\
\hline - Height, $H_{F P T-3}$ & $8 \mathrm{ft} 6$ in & “، \\
\hline - Height of Waste Header \#2 discharge & $6 \mathrm{ft} 10 \mathrm{in}$ & “ \\
\hline \multicolumn{3}{|l|}{ Water } \\
\hline - surface tension, $\sigma_{\mathrm{H} 2 \mathrm{O}}$ & $0.073 \mathrm{~N} / \mathrm{m}$ & Ref. 15 \\
\hline \multicolumn{3}{|l|}{ Air } \\
\hline - Density@35 ${ }^{\circ} \mathrm{C}, \rho_{G}$ & $0.0716 \mathrm{lb} / \mathrm{ft}^{3}$ & Ref. 10 \& extrapolation \\
\hline . Viscosity@35 ${ }^{\circ} \mathrm{C}, \mu_{G}$ & $1.2633 \mathrm{E}-5 \mathrm{lb} / \mathrm{ft} / \mathrm{sec}$ & Ref. 10 \\
\hline \multicolumn{3}{|l|}{$50 \mathrm{wt} \%$ nitric acid } \\
\hline - Density, $\rho_{L}$ & $81.78 \mathrm{lb} / \mathrm{ft}^{3}$ & Ref. 10 \\
\hline - Viscosity@35 ${ }^{\circ} \mathrm{C}, \mu_{L}$ & $1.277 \mathrm{E}-3 \mathrm{lb} / \mathrm{ft} / \mathrm{sec}$ & “ \\
\hline - Surface tension, $\sigma_{L}$ & $6.7858 \mathrm{E}-2 \mathrm{~N} / \mathrm{m}$ & Ref. 15 \& extrapolation \\
\hline - Vapor pressure @ $35^{\circ} \mathrm{C}, V P_{H N O 3}$ & $0.8 \mathrm{mmHg}$ & Ref. 10 \\
\hline Universal Gas Constant & $0.2897 \mathrm{ft}^{3} \mathrm{~atm} / \mathrm{K} / \mathrm{Kg}$ mole & \\
\hline
\end{tabular}

The pressure drop in a straight pipe is proportional to the square of the fluid velocity by Eq. (8). Therefore, from the definition of $X$ given by Eq. (6), it is expected that as the value of $X$ is decreased, the superficial liquid velocity, $v_{L}$, would decrease, while that of the gas, $v_{G}$, would increase. As shown in Figure 5, this was indeed the case for the calculated superficial liquid velocities, as they decreased with decreasing $X$. On the other hand, the calculated superficial gas velocities increased monotonically, as expected, as the value of $X$ was decreased to 0.35 ; however, at $X<0.35$, they began to decrease while oscillating, thereby giving rise to a maximum superficial gas velocity at $X=0.35$. 
TABLE 3. Results of Hydraulic Calculations for Maximum Air Flow.

\begin{tabular}{|c|c|c|c|c|c|c|c|c|c|c|}
\hline$X$ & $R_{L}$ & $\begin{array}{c}\text { Flow } \\
\text { Regime }\end{array}$ & $Y_{G}$ & $Y_{L}$ & $h_{L}^{G}$ & $h_{L}^{L}$ & $v_{G}$ & $v_{L}$ & $R e_{G}$ & $\begin{array}{l}\text { Two-Phase } \\
\text { Flow Pattern }\end{array}$ \\
\hline 1.0 & 0.23 & V-T & 13 & 13 & 3.35 & 3.35 & 0.55 & 0.916 & 797 & Plug \\
\hline 0.7 & 0.20 & V-T & 8.5 & 17.35 & 5.133 & 2.515 & 0.83 & 0.773 & 1,203 & “ \\
\hline 0.48 & 0.15 & V-T & 6 & 26 & 7.307 & 1.686 & 1.182 & 0.622 & 1,718 & “ \\
\hline 0.4 & 0.14 & V-T & 5 & 30 & 8.78 & 1.463 & 1.43 & 0.571 & 2,072 & “ \\
\hline $\mathbf{0 . 3 5}$ & $\mathbf{0 . 1 2 9}$ & T-T & $\mathbf{7 . 2}$ & $\mathbf{5 8 . 8}$ & $\mathbf{6 . 1 1}$ & $\mathbf{0 . 7 4 8}$ & $\mathbf{1 . 5 7 3}$ & $\mathbf{0 . 3 9 4}$ & $\mathbf{2 , 2 8 0}$ & $\begin{array}{c}\text { Plug/ } \\
\text { Stratified }\end{array}$ \\
\hline 0.3 & 0.115 & T-T & 6.3 & 70 & 7 & 0.63 & 1.126 & 0.353 & 1,632 & Stratified \\
\hline 0.2 & 0.09 & T-T & 5 & 125 & 8.88 & 0.355 & 1.4293 & 0.251 & 2,067 & “ \\
\hline 0.1 & 0.055 & T-T & 3.3 & 330 & 13.72 & 0.1372 & 1.398 & 0.143 & 2,026 & “ \\
\hline
\end{tabular}

From Table 3, it is also noted that the two-phase flow transitions from plug to stratified flow at $X=0.35$. In other words, the calculated superficial gas velocities followed the predicted trend only in plug flow but oscillated in stratified flow. The plug-to-stratified flow transition is significant in that the two-phase flow is no longer distributed or intermittent but totally segregated in the latter flow pattern. This is why the assumption of a homogeneous mixture made in this study for the calculation of the two-phase density using Eq. (12) is not valid for stratified flow. Based on these results, it is therefore concluded that the maximum superficial air velocity through the Waste Header \#2 is $1.573 \mathrm{ft} / \mathrm{sec}$ at the transition point between the plug and stratified flows.

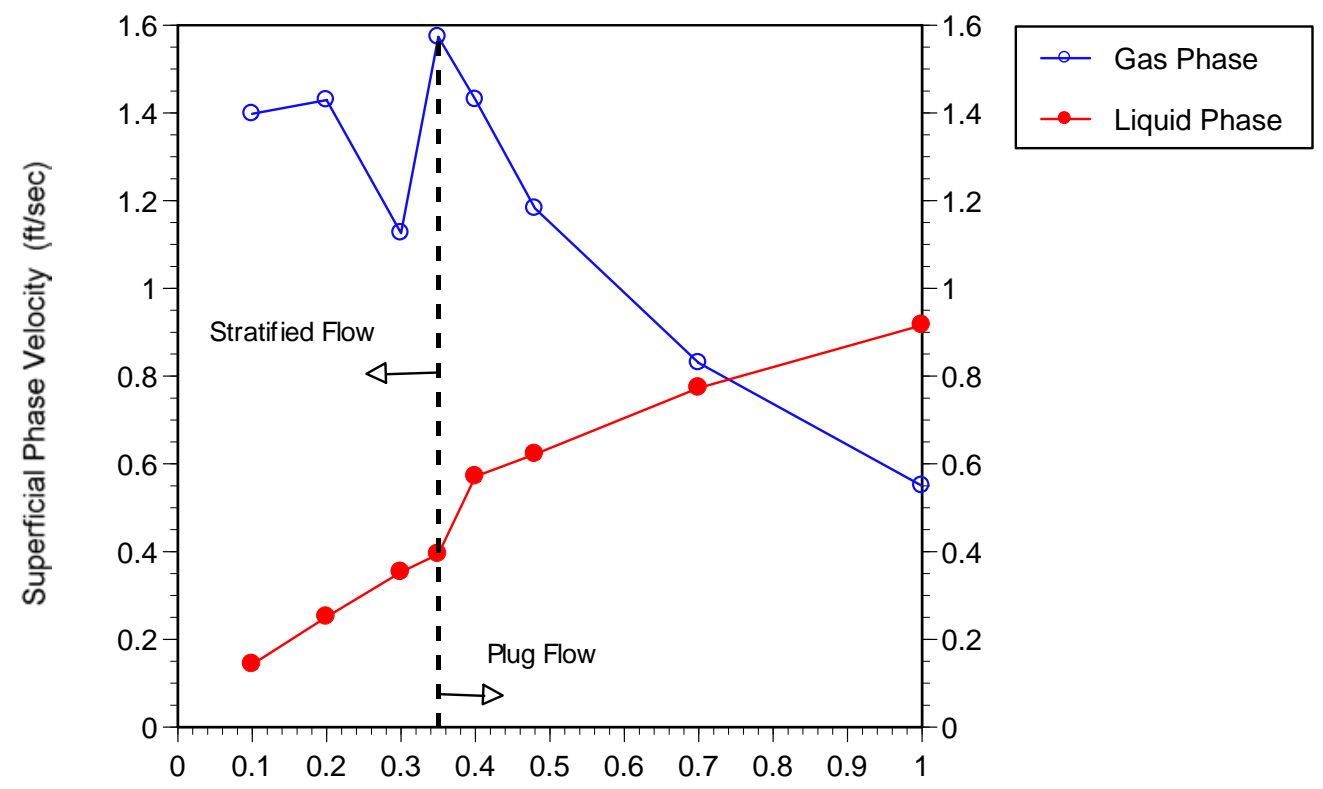

Lockhart-Martinelli Parameter, $\mathrm{X}$

FIGURE 5. Calculated Superficial Phase Velocities vs. L-M Parameter $X$. 
It was stated earlier that the pressure drop predictions based on the L-M correlation are in general known to be high for stratified, wavy, and slug flows [10]. It means that for the given profiles of $Y_{G}$ and $Y_{L}$ in Figure 1, the single-phase pressure drop predictions from the inverse application of the L-M correlation would tend to be low. This may explain why the calculated superficial liquid velocities fell abruptly at $X \leq 0.35$. Likewise, the actual superficial gas velocities for stratified flow may also be higher than those shown in Figure 5 at $X \leq 0.35$; however, they are still likely to remain below that at $X=0.35$ and oscillatory.

Furthermore, for all the $X^{\prime}$ 's considered in this study, the superficial liquid flow was always in the turbulence regime mainly due to its density that is more than 3 orders magnitude higher than that of the gas. On the other hand, the superficial gas flow was in the viscous regime when the predicted two-phase flow was intermittent and in the turbulence regime when it was segregated. However, it is shown in Table 3 that the gas phase was still assumed to be in the viscous regime at $X=0.4$ even though its calculated Reynolds number of 2,072 was slightly above the criterion set for turbulence at $R e=2,000$. This was because the calculated Reynolds number with the assumption of turbulence was only 1,283, which is off from the turbulence criterion in the other direction by a much greater margin, and a choice between the viscous and turbulence regimes had to be made in order to use Figure 1.

Likewise, at $X=0.3$, the gas phase was assumed to be in the turbulence regime even though its calculated Reynolds number of 1,632 was below the turbulence criterion. Again, this was because the calculated Reynolds number with the assumption of viscous flow was 2,556, which is above the turbulence criterion by a wider margin than that calculated with the assumption of turbulence is below the turbulence criterion.

\subsection{Calculation of Maximum Air Emission}

The maximum volumetric flow rate of air through the Waste Header \#2 was calculated next from the maximum superficial gas velocity as:

$$
\begin{aligned}
Q_{G, \max } & =v_{G, \max } A \\
& =\left(1.573 \frac{f t}{\mathrm{sec}}\right)\left(0.0513 f t^{2}\right)\left(\frac{60 \mathrm{sec}}{\min }\right) \\
& =4.84 \frac{f t^{3}}{\mathrm{~min}}
\end{aligned}
$$

where $\mathrm{A}$ is the cross-sectional area of pipe. It turns out that the maximum air flow thus calculated is equal to $5 \%$ of the total air inleakage to the FPT-3, which was estimated earlier to be $96.5 \mathrm{cfm}$. This 5\% allocation may look like a small fraction at first but is 
actually conservatively high, considering the fact that the FPT-3 has many other penetrations with much less flow resistance than the Waste Header \#2, which is also being pulled by a strong suction on the other end.

The maximum air emission of nitric acid was then calculated based on thermodynamic equilibrium, i.e., by fully saturating the maximum air flow just calculated above with the equilibrium vapor of $50 \mathrm{wt} \%$ nitric acid solution using the ideal gas law:

$$
\dot{n}_{\mathrm{HNO}_{3}}=\frac{Q_{G, \max } V P_{\mathrm{HNO}_{3}}}{R T}
$$

where $V P_{H N O 3}$ is the vapor pressure of $50 \mathrm{wt} \%$ nitric acid solution, and $R$ the universal gas constant, and $T$ the temperature in Kelvin. After substituting in appropriate values from Table 2 and further making necessary conversions, the maximum air emission projection of nitric acid was obtained as follows:

$$
\begin{aligned}
& \dot{n}_{\mathrm{HNO}_{3}}=\frac{\left(4.84 \frac{\mathrm{ft}^{3}}{\mathrm{~min}}\right)\left(\frac{60 \mathrm{~min}}{\mathrm{hr}}\right)(0.8 \mathrm{mmHg})\left(\frac{\mathrm{atm}}{760 \mathrm{mmHg}}\right)}{\left(2.8978 \frac{\mathrm{atm} \mathrm{ft}}{\text { Kgmole K}^{3}}\right)(308 \mathrm{~K})} \\
& =3.425 E-4 \frac{\text { Kgmole }}{h r} \\
& \dot{m}_{\mathrm{HNO} 3}=\left(3.425 E-4 \frac{\text { Kgmole }}{h r}\right)\left(\frac{1,000 \text { gmole }}{\text { Kgmole }}\right)\left(\frac{63 g}{\text { gmole }}\right)\left(\frac{\mathrm{lb}}{453.6 \mathrm{~g}}\right) \\
& =0.048 \frac{l b}{h r}
\end{aligned}
$$

This maximum air emission projection of nitric acid is indeed conservative, since it was derived based on the worst-case scenario of ambient air flowing in the direction of the FTP-3 at its maximum possible rate and becoming fully equilibrated with the fresh nitric acid solution in the deposit-free header. Nevertheless, the resulting air emission projection was still just below the current exemption limit of $0.05 \mathrm{lb} / \mathrm{hr}$ for permit applications. As a result, it is concluded that there will be no realistic probability that the nitric acid emission at the stack of the FPP-2/3 ventilation system ever exceeds the exemption limit. 


\subsection{Staged Model of Scale Formation and Dissolution}

In this section, a process model of scale formation and dissolution is developed using the ESP software v6.6, licensed by OLI Systems, Inc. ${ }^{13}$ The ESP software is being widely used in the chemical process industry to predict the thermodynamic equilibrium behavior of multicomponent electrolyte systems. The purpose of ESP modeling in this study was to determine the chemical makeup of the scale material forming inside the Waste Header \#2 and to see how the presence of scale material affects the air emission. In doing so, it is hoped that the assumption made earlier that the air emission decreases with increasing presence of scale material be confirmed, thereby further substantiating the conservatism built into the maximum air emission projection made in the preceding section.

Every ESP model built is made up of two parts: a chemistry model that determines what chemical species and equilibrium reactions to include and a flowsheet model that describes all the unit operations involved and the connectivity among them. The input to the chemistry model is the chemical composition of the six F-Canyon regular waste streams, which is discussed next.

\subsubsection{F-Canyon Waste Compositions}

The chemical constituents that make up the six F-Canyon regular waste (FCANRW) streams are shown in Table 4. The individual component flows shown are the time-averaged values set based on the chemical composition and processing rate data given in the WCP for the six regular waste types. ${ }^{14}$ There was one exception; no actual data was given on the processing rate of the Coating Waste, so its rate was set based on the assumed operating frequency of one dissolver run per every 5 months at a rate of 5,000 gallons per dissolver run. Furthermore, the given density of $1.16 \mathrm{~g} / \mathrm{ml}$ for the General-Purpose (GP) evaporator concentrate is an assumed value. Since mercuric nitrate, $\mathrm{Hg}\left(\mathrm{NO}_{3}\right)_{2}$, was not found in the OLI software database, it was replaced with $\mathrm{Hg}(\mathrm{OH})_{2}$ in the model.

Thus, the total flow rates given in the far right-hand column of Table 4 represent the time-averaged molar component flows of the composite FCAN-RW stream, which were subsequently used as the input to the staged process model. The componentby-component contributions of each waste type to the composite waste stream are given in Table 5. The composite waste stream is seen to be highly basic, since its caustic content is nearly $35 \mathrm{wt} \%$ of the total solids, while the common sodium salts of nitrate, sulfate, carbonate, etc. constitute $50 \mathrm{wt} \%$ of the total solids. Ferric hydroxides, which are believed to be the main culprit of the Waste Header \#2 plugging, make up just over $6 \mathrm{wt} \%$ of the total solids in the composite waste stream, and nearly $98 \%$ of ferric hydroxides come from the LAW concentrate. It is also seen that the total uranium salt content is $4 \mathrm{wt} \%$ of the total solids, and $70 \%$ of the uranium comes from the General-Purpose evaporator concentrate. It should be noted that these six regular waste streams shown in Table 4 represent the approved reference waste streams of the past and should bound the current waste streams. 


\section{TABLE 4. Chemical Compositions and Processing Rates of Six F-Canyon Regular Waste Streams.}

\begin{tabular}{|c|c|c|c|c|c|c|c|}
\hline Species & $\begin{array}{r}\text { LAW conc } \\
\text { (gmoles/hr) }\end{array}$ & $\begin{array}{r}\text { HLW conc } \\
\text { (gmoles/hr) }\end{array}$ & $\begin{array}{r}\text { Coating waste } \\
\text { (gmoles/hr) }\end{array}$ & $\begin{array}{r}\text { GP conc } \\
\text { (gmoles/hr) }\end{array}$ & $\begin{array}{r}\text { Lab waste } \\
\text { (gmoles/hr) }\end{array}$ & $\begin{array}{r}\text { FB-Line waste } \\
\text { (gmoles/hr) }\end{array}$ & $\begin{array}{r}\text { Total } \\
\text { (gmoles/hr) }\end{array}$ \\
\hline $\mathrm{NaNO} 2$ & & & $2.7842 E+00$ & 2.6191E-01 & & & $3.0461 \mathrm{E}+00$ \\
\hline $\mathrm{NaNO} 3$ & 1.2173E+01 & $4.6861 \mathrm{E}+01$ & $1.1223 E+01$ & $2.7898 E+01$ & $2.1475 E+01$ & $6.6801 E+00$ & $1.2631 \mathrm{E}+02$ \\
\hline $\mathrm{NaOH}$ & $2.3932 E+01$ & $1.8729 \mathrm{E}+01$ & $7.4395 E+00$ & $5.4156 \mathrm{E}+01$ & $7.3539 E+01$ & $8.0299 E+01$ & $2.5810 \mathrm{E}+02$ \\
\hline $\mathrm{Na} 2 \mathrm{SO} 4$ & 1.6523E+01 & 5.4189E-01 & & $1.6725 E+00$ & & & $1.8738 E+01$ \\
\hline $\mathrm{Na} 2 \mathrm{C} 2 \mathrm{O} 4$ & & & & $1.8435 E+00$ & & & $1.8435 \mathrm{E}+00$ \\
\hline $\mathrm{NaAlO} 2$ & & 1.1737E+00 & $7.0308 \mathrm{E}+00$ & $2.0241 \mathrm{E}+00$ & & & $1.0229 E+01$ \\
\hline $\mathrm{Na} 2 \mathrm{CO} 3$ & & & & $5.4784 \mathrm{E}+00$ & & & $5.4784 \mathrm{E}+00$ \\
\hline TBP & & & & $3.1150 \mathrm{E}-01$ & & & $3.1150 \mathrm{E}-01$ \\
\hline $\mathrm{Al}(\mathrm{NO} 3) 3$ & & & & 7.7897E-01 & & & 7.7897E-01 \\
\hline $\mathrm{Fe}(\mathrm{NO} 3) 3$ & & & & 5.5750E-01 & & & 5.5750E-01 \\
\hline $\mathrm{Fe}(\mathrm{OH}) 3$ & $1.6530 E+01$ & 3.6011E-01 & & & & & $1.6890 E+01$ \\
\hline $\mathrm{Fe} 2(\mathrm{SO} 4) 3$ & & & & 5.5750E-01 & & & 5.5750E-01 \\
\hline $\mathrm{Hg}(\mathrm{NO} 3) 2$ & & & & 3.5363E-01 & & & 3.5363E-01 \\
\hline $\mathrm{KF}$ & & & & $1.4279 E+00$ & & & $1.4279 \mathrm{E}+00$ \\
\hline $\mathrm{KMnO} 4$ & & & & $1.0499 E+00$ & & & $1.0499 \mathrm{E}+00$ \\
\hline $\mathrm{Mn}(\mathrm{NO} 3) 2$ & & 3.2261E-02 & & & & & $3.2261 \mathrm{E}-02$ \\
\hline $\mathrm{NH} 2 \mathrm{OH}$ & & & & 8.6415E-01 & & & 8.6415E-01 \\
\hline N2 & & & & $3.3450 E+00$ & & & $3.3450 \mathrm{E}+00$ \\
\hline NO & & & & 5.5750E-01 & & & $5.5750 \mathrm{E}-01$ \\
\hline UO2(OH)2 & & $1.1392 E+00$ & & & & & $1.1392 \mathrm{E}+00$ \\
\hline UO2(NO3)2 & & & & $2.1053 E+00$ & & & $2.1053 E+00$ \\
\hline $\mathrm{H} 2 \mathrm{O}$ & $1.0618 E+03$ & $7.7440 E+02$ & $2.5556 \mathrm{E}+02$ & $2.2810 E+03$ & 1.1826E+03 & $8.4050 E+02$ & $6.3959 E+03$ \\
\hline Total & $1.1310 \mathrm{E}+03$ & $8.4323 E+02$ & $2.8404 \mathrm{E}+02$ & $2.3862 E+03$ & $1.2776 \mathrm{E}+03$ & $9.2748 \mathrm{E}+02$ & $6.8496 \mathrm{E}+03$ \\
\hline Density $(\mathrm{g} / \mathrm{ml})$ & 1.2 & 1.22 & 1.26 & 1.16 & 1.24 & 1.2 & \\
\hline $\begin{array}{l}\text { Processing Rate } \\
\text { (gal/month) }\end{array}$ & 4000 & 3000 & 1000 & 8000 & 4000 & 3000 & \\
\hline
\end{tabular}

TABLE 5. Dry-Basis Composition of Composite F-Canyon Regular Waste and Component-by-Component Contributions by Each Waste Stream.

\begin{tabular}{|c|c|c|c|c|c|c|c|c|}
\hline Species & $\begin{array}{r}\text { Composite } \\
\text { (wt\% dry) }\end{array}$ & $\begin{array}{r}\text { LAW conc } \\
(\% \text { total })\end{array}$ & $\begin{array}{r}\text { HLW conc } \\
(\% \text { total })\end{array}$ & $\begin{array}{r}\text { Coating waste } \\
(\% \text { total) }\end{array}$ & $\begin{array}{l}\text { GP conc } \\
\text { (\% total) }\end{array}$ & $\begin{array}{r}\text { Lab waste } \\
(\% \text { total })\end{array}$ & $\begin{array}{r}\text { FB-Line waste } \\
(\% \text { total })\end{array}$ & $\begin{array}{r}\text { Total Solids } \\
(\% \text { total })\end{array}$ \\
\hline $\mathrm{NaNO} 2$ & 0.71 & & & 91.40 & 8.60 & & & 100.00 \\
\hline $\mathrm{NaNO} 3$ & 36.17 & 9.64 & 37.10 & 8.88 & 22.09 & 17.00 & 5.29 & 100.00 \\
\hline $\mathrm{NaOH}$ & 34.84 & 9.27 & 7.26 & 2.88 & 20.98 & 28.49 & 31.11 & 100.00 \\
\hline $\mathrm{Na} 2 \mathrm{SO} 4$ & 8.97 & 88.18 & 2.89 & & 8.93 & & & 100.00 \\
\hline $\mathrm{Na} 2 \mathrm{C} 2 \mathrm{O} 4$ & 0.83 & & & & 100.00 & & & 100.00 \\
\hline $\mathrm{NaAlO} 2$ & 2.82 & & 11.47 & 68.74 & 19.79 & & & 100.00 \\
\hline $\mathrm{Na} 2 \mathrm{CO} 3$ & 1.96 & & & & 100.00 & & & 100.00 \\
\hline TBP & 0.28 & & & & 100.00 & & & 100.00 \\
\hline $\mathrm{Al}(\mathrm{NO} 3) 3$ & 0.56 & & & & 100.00 & & & 100.00 \\
\hline $\mathrm{Fe}(\mathrm{NO} 3) 3$ & 0.45 & & & & 100.00 & & & 100.00 \\
\hline $\mathrm{Fe}(\mathrm{OH}) 3$ & 6.08 & 97.87 & 2.13 & & & & & 100.00 \\
\hline $\mathrm{Fe} 2(\mathrm{SO} 4) 3$ & 0.75 & & & & 100.00 & & & 100.00 \\
\hline $\mathrm{Hg}(\mathrm{NO} 3) 2$ & 0.28 & & & & 100.00 & & & 100.00 \\
\hline $\mathrm{KF}$ & 0.28 & & & & 100.00 & & & 100.00 \\
\hline $\mathrm{KMnO} 4$ & 0.56 & & & & 100.00 & & & 100.00 \\
\hline $\mathrm{Mn}(\mathrm{NO} 3) 2$ & 0.02 & & 100.00 & & & & & 100.00 \\
\hline $\mathrm{NH} 2 \mathrm{OH}$ & 0.10 & & & & 100.00 & & & 100.00 \\
\hline N2 & 0.32 & & & & 100.00 & & & 100.00 \\
\hline NO & 0.06 & & & & 100.00 & & & 100.00 \\
\hline UO2(OH)2 & 1.17 & & 100.00 & & & & & 100.00 \\
\hline UO2(NO3)2 & 2.80 & & & & 100.00 & & & 100.00 \\
\hline Total & 100.00 & & & & & & & \\
\hline
\end{tabular}




\subsubsection{Chemistry Model}

The ESP chemistry model of the Waste Header \#2 scale formation and dissolution was developed based on those 21 waste components listed in Table 4 or 5 . The total number of species included in the resulting chemistry model was 137, including 15 vapor, 35 aqueous, 67 ionic, and 20 solids species, as shown in Table 6 . Since the relevant aqueous chemistry of this study covers the entire $\mathrm{pH}$ range from 0 (scale dissolution) to 14 (scale formation), it was necessary to augment the default OLI software database PUBLIC with the private database HNO3DB, which was recently optimized for the 6-component acidic system of $\mathrm{NaNO}_{3}-\mathrm{KNO}_{3}-\mathrm{CsNO}_{3}-\mathrm{Al}\left(\mathrm{NO}_{3}\right)_{3}$ $\mathrm{HNO}_{3}-\mathrm{H}_{2} \mathrm{O}^{14}$

TABLE 6. Species Included in Waste Header \#2 Chemistry Model.

\begin{tabular}{|c|c|c|c|}
\hline Vapor & $\mathrm{N} 2 \mathrm{AQ}$ & FEIIIHC2O4ION & SO4ION \\
\hline CO2VAP & $\mathrm{N} 2 \mathrm{O} 4 \mathrm{AQ}$ & FEIIIION & UO22OH2ION \\
\hline H2F2VAP & NAFAQ & FEIIINO3ION & UO23OH5ION \\
\hline H2OVAP & NAHCO3AQ & FEIIIOH2ION & UO2C2O42ION \\
\hline H2SO4VAP & NANO3AQ & FEIIIOH4ION & UO2C2O43ION \\
\hline HDROXAMNVAP & NO2AQ & FEIIIOHION & UO2CO32ION \\
\hline HFVAP & NOAQ & FEIIISO4ION & UO2CO33ION \\
\hline HNO2VAP & $\mathrm{O} 2 \mathrm{AQ}$ & FION & UO2F3ION \\
\hline HNO3VAP & OXALACAQ & HCO3ION & UO2F4ION \\
\hline N2O4VAP & SO3AQ & HF2ION & UO2FION \\
\hline N2VAP & TRIBUTPHOSAQ & HGFION & UO2ION \\
\hline NO2VAP & UO2C2O4AQ & HGION & UO2OHION \\
\hline NOVAP & UO2CO3AQ & HGOH3ION & UO2SO42ION \\
\hline O2VAP & UO2F2AQ & HGOHION & \\
\hline SO3VAP & $\mathrm{UO} 2 \mathrm{OH} 2 \mathrm{AQ}$ & HHDRAMION & Solids \\
\hline \multirow[t]{2}{*}{ TRIBUTPHOSVAP } & UO2SO4AQ & HION & ALOH3PPT \\
\hline & & HOXALATION & FE2SO43PPT \\
\hline Aqueous & lons & HSO4ION & FEIIIF3PPT \\
\hline $\mathrm{H} 2 \mathrm{O}$ & ALF2ION & $\mathrm{KION}$ & FEIIIOHЗРPT \\
\hline ALF3AQ & ALF4ION & KSO4ION & HGOPPT \\
\hline ALOH3AQ & ALF5ION & MNC2O42ION & MNOH2PPT \\
\hline $\mathrm{CO} 2 \mathrm{AQ}$ & ALF6ION & MNC2O43ION & NA2C2O4PPT \\
\hline FEIIIF3AQ & ALFION & MNION & NA2CO3PPT \\
\hline FEIIIOH3AQ & ALION & MNNO3ION & NA2U2O7PPT \\
\hline $\mathrm{H} 2 \mathrm{~F} 2 \mathrm{AQ}$ & ALOH2ION & MNOH3ION & NA3FSO4PPT \\
\hline $\mathrm{H} 2 \mathrm{SO} 4 \mathrm{AQ}$ & ALOH4ION & MNOH4ION & NA6SO42CO3PPT \\
\hline HDROXAMNAQ & ALOHION & MNOHION & NAALCO3OH2PPT \\
\hline HFAQ & ALSO42ION & MNVIIO4ION & NANO3PPT \\
\hline HGC2O4AQ & ALSO4ION & NA2FION & ALNO33.9H2O \\
\hline $\mathrm{HGOH} 2 \mathrm{AQ}$ & CO3ION & NACO3ION & FEIIINO33.9H2O \\
\hline $\mathrm{HNO} 2 \mathrm{AQ}$ & FEIII2OH2ION & NAION & $\mathrm{NA} 2 \mathrm{CO} 3.10 \mathrm{H} 2 \mathrm{O}$ \\
\hline HNO3AQ & FEIIIC2O42ION & NASO4ION & $\mathrm{NA} 2 \mathrm{CO} 3.1 \mathrm{H} 2 \mathrm{O}$ \\
\hline KHSO4AQ & FEIIIC2O43ION & NO2ION & $\mathrm{NA} 2 \mathrm{CO} 3.7 \mathrm{H} 2 \mathrm{O}$ \\
\hline MNC2O4AQ & FEIIIC2O4ION & NO3ION & UO2NO32.6H2O \\
\hline MNNO32AQ & FEIIIF2ION & OHION & UO2NO32.6H2O \\
\hline $\mathrm{MNOH} 2 \mathrm{AQ}$ & FEIIIFION & OXALATION & \\
\hline MNSO4AQ & & & \\
\hline
\end{tabular}


The equilibrium speciation of the composite FCAN-RW among the aqueous, solid, and gas phases was calculated by solving 114 equilibrium relationships for the 137 model species simultaneously with the mass balance equations. Considering the fact that the convergence of ESP models is most sensitive to the number of solids species chosen, the list of solids species included in the present model is quite comprehensive, since it includes all the relevant salts of sodium and uranium, including the hydrates, and the anticipated precipitates of ferric and aluminum hydroxides. All the iron species were assumed to be in the +3 oxidation state and no redox reactions were considered in this study.

\subsubsection{Process Model}

A schematic of the staged model of scale formation and dissolution is shown in Figure 6. The Waste Header \#2 is represented by the SEPATATE block, where the equilibrium speciation of the composite FCAN-RW stream is computed in the presence of ambient air. The quantity of scale material thus predicted to form is then distributed equally among 5 dissolver stages, thereby simulating a uniform spatial distribution of the scale material throughout the Waste Header \#2.

Each dissolver stage is made up of a MIX block used to carry out the acid dissolution and a SEPARATE block used to calculate the air emission based on the vapor-liquid equilibrium (VLE) between the spent acid solution and the air flow. The fresh nitric acid enters the MIX block of Stage 1, where part or all the scale material allocated to that stage is dissolved, depending on the acid-to-scale flow ratio assumed. The spent acid effluent from Stage 1 then enters Stage 2 and dissolves an additional quantity of scale material. The scale dissolution and VLE process will be repeated in each stage until the free acid is completely depleted.

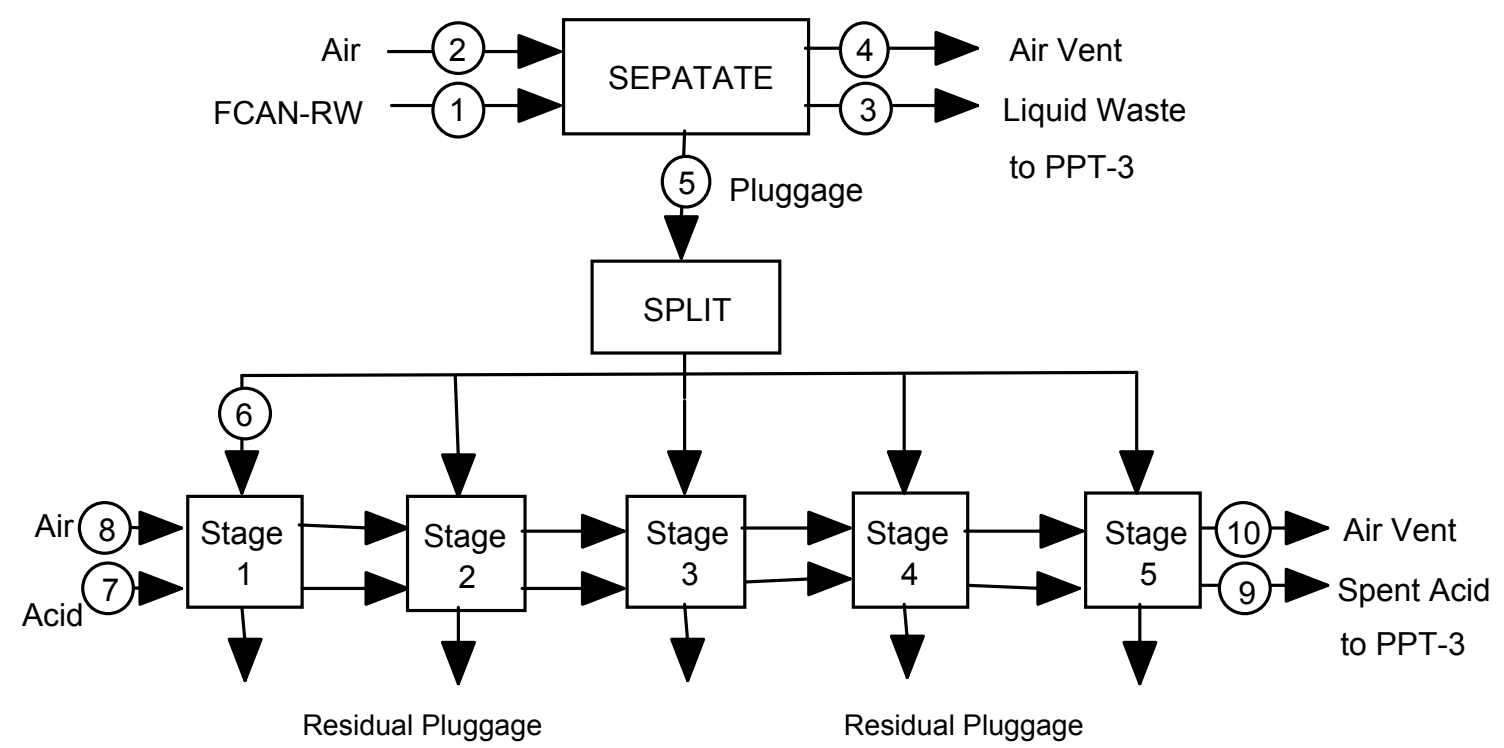

FIGURE 6. Schematic of Waste Header \#2 Scale Formation and Dissolution Model. 


\subsubsection{Model Execution}

The ESP process model described in the preceding section is a steady state model, and all the input flows must be given in terms of instantaneous or time-averaged flow rates. As an illustration, the model was run for the case of L-M parameter $X=$ 0.48 . The instantaneous gas-phase velocity for this case is given as $1.182 \mathrm{ft} / \mathrm{sec}$ in Table 3, and the corresponding molar flow rate of air is then:

$$
\begin{aligned}
\dot{n}_{G} & =\frac{\dot{Q}_{G} P}{R T} \\
& =\frac{\left(1.182 \frac{f t}{\mathrm{sec}}\right)\left(0.0513 \mathrm{ft}^{2}\right)\left(\frac{3,600 \mathrm{sec}}{\mathrm{hr}}\right)(1 \mathrm{~atm})}{\left(0.0028978 \frac{\mathrm{atm} \mathrm{ft}^{3}}{\mathrm{gmole} \mathrm{K}^{2}}\right)(308 \mathrm{~K})} \\
& =245 \frac{\text { gmole }}{\mathrm{hr}}
\end{aligned}
$$

The molar feed rate of $50 \mathrm{wt} \%$ nitric acid to Stage 1 was set based on the instantaneous liquid-phase velocity of $0.622 \mathrm{ft} / \mathrm{sec}$, which was calculated earlier in conjunction with the gas-phase velocity of $1.182 \mathrm{ft} / \mathrm{sec}$ at $X=0.48$ (Table 3):

$$
\begin{aligned}
\dot{n}_{L} & =\dot{Q}_{L} \rho_{L} / \overline{M W} \\
& =\left(0.622 \frac{f t}{\mathrm{sec}}\right)\left(0.0513 f t^{2}\right)\left(81.78 \frac{\mathrm{lb}}{f t^{3}}\right)\left(3,600 \frac{\mathrm{sec}}{h r}\right)\left(\frac{453.6 g}{l b}\right)\left(\frac{\text { gmole }}{28.018 g}\right) \\
& =152,084 \frac{\text { gmole }}{h r}
\end{aligned}
$$

where $\overline{M W}$ is the mean molecular weight of $50 \mathrm{wt} \%$ nitric acid solution, which was estimated to be $28.018 \mathrm{~g} / \mathrm{gmole}$. As a comparison, the highest time-averaged molar feed rate of acid based on the Waste Header \#2 cleaning procedure given earlier is: ${ }^{1}$

$$
\begin{aligned}
\dot{n}_{L} & =\frac{(9,000 \mathrm{lb})(453.6 \mathrm{~g} / \mathrm{lb})}{(28.018 \mathrm{~g} / \text { gmole })(2 \mathrm{hr})} \\
& =72,853 \frac{\text { gmole }}{\mathrm{hr}}
\end{aligned}
$$


where the minimum duration for acid cleaning was assumed to be 2 hours. ${ }^{3}$ It is noted that this time-averaged acid flow is less than $50 \%$ of the instantaneous flow estimated based on the liquid-phase velocity of $0.622 \mathrm{ft} / \mathrm{sec}$. Therefore, using the latter acid flow as the model input should be at least as conservative from the air emission standpoint as using the former acid flow. In fact, as long as the spent acid effluent from Stage 5 contains any residual acid, it is the rate of air flow that determines the acid emission, not the acid flow.

With the air and acid flow rates now set, the model was next run at various molar flow ratios of waste-to-acid feeds, ranging from 0 (for the acid-only case) to 24 . Additional bases and assumptions used in the model run included:

- Both liquid and gas temperatures in the Waste Header $\# 2$ are constant at $35^{\circ} \mathrm{C}$.

- The pressure in the waste header is constant at $1 \mathrm{~atm}$, i.e., losses due to fluid friction and elevation drop are ignored.

- Ambient air is $30 \%$ saturated at $70{ }^{\circ} \mathrm{F}$ or $21^{\circ} \mathrm{C}$.

- The air flow leaving each stage is saturated with the undissociated nitric acid.

\subsubsection{Model Results}

The results of the ESP model runs at the L-M parameter $X=0.48$ are summarized in Table 7. Furthermore, the equilibrium speciation results for the ten major streams shown in Figure 6 are also attached in Appendix for the case of waste-to-acid molar feed ratio of 16.4. As expected, the model predicted ferric hydroxide $\left(\mathrm{Fe}(\mathrm{OH})_{3}\right)$ to be the primary constituent of the scale material (Stream 5/6). Also predicted to form in the composite FCAN-RW stream are the precipitates of sodium diuranate $\left(\mathrm{Na}_{2} \mathrm{U}_{2} \mathrm{O}_{7}\right)$ and mercuric oxide $(\mathrm{HgO})$ at one- and two-orders of magnitude lower molar concentrations than ferric hydroxide, respectively. On the mass basis, the scale material was predicted to consist of $63.2 \% \mathrm{Fe}(\mathrm{OH})_{3}, 34.4 \% \mathrm{Na}_{2} \mathrm{U}_{2} \mathrm{O}_{7}$, and $2.4 \% \mathrm{HgO}$.

The fresh nitric acid (Stream 7) enters Stage 1 at $10.2 \mathrm{M}$, and the remaining acidity in the final spent acid effluent from Stage 5 (Stream 9) is shown in Figure 7 to decrease linearly with increasing waste-to-acid feed ratio. This linear trend was expected since the acid requirement should increase with increasing feed or scale flow according to the dissolution stoichiometry for a particular solid, e.g., Reaction (3) for ferric hydroxide. It is seen that the acid concentration in the final spent acid effluent from Stage 5 fell to near zero as the waste-to-acid feed ratio was increased to 24 . 
TABLE 7. Results of ESP Model Runs at L-M Parameter $X=0.48$.

$50 \%$ nitric acid flow rate (mole/hr) = 152087

$\begin{array}{rrrrr}\begin{array}{r}\text { FCAN-RW flow } \\ (\mathrm{mole} / \mathrm{hr})\end{array} & \begin{array}{r}\text { waste-to-acid feed ratio } \\ (\text { mole/mole })\end{array} & \begin{array}{r}\text { scale flow } \\ (\mathrm{mole} / \mathrm{hr})\end{array} & \begin{array}{r}\text { HNO3 Emission } \\ (\mathrm{lb} / \mathrm{hr})\end{array} & \begin{array}{r}\text { Spent Acid HNO3 } \\ (\mathrm{M})\end{array} \\ 0.00 \mathrm{E}+00 & 0.00 & 0 & 0.0360 & 10.13 \\ 5.00 \mathrm{E}+05 & 3.29 & 1435 & 0.0340 & 8.68 \\ 1.00 \mathrm{E}+06 & 6.58 & 2869 & 0.0330 & 7.22 \\ 1.50 \mathrm{E}+06 & 9.86 & 4304 & 0.0320 & 5.82 \\ 2.00 \mathrm{E}+06 & 13.15 & 5739 & 0.0220 & 4.43 \\ 2.50 \mathrm{E}+06 & 16.44 & 7174 & 0.0140 & 3.07 \\ 3.00 \mathrm{E}+06 & 19.73 & 8608 & 0.0070 & 1.72 \\ 3.50 \mathrm{E}+06 & 23.01 & 10043 & 0.0014 & 0.39 \\ 3.60 \mathrm{E}+06 & 23.67 & 10300 & 0.0005 & 0.15 \\ 3.65 \mathrm{E}+06 & 24.00 & 10474 & 0.0002 & 0.05 \\ 3.68 \mathrm{E}+06 & 24.20 & 10560 & 0.0001 & 0.03 \\ 3.68 \mathrm{E}+06 & 24.20 & 10588 & 0.0001 & 0.025 \\ 3.70 \mathrm{E}+06 & 24.30 & 10603 & 0.0001 & 0.022 \\ 3.70 \mathrm{E}+06 & 24.33 & 10617 & 0.0001 & 0.022\end{array}$

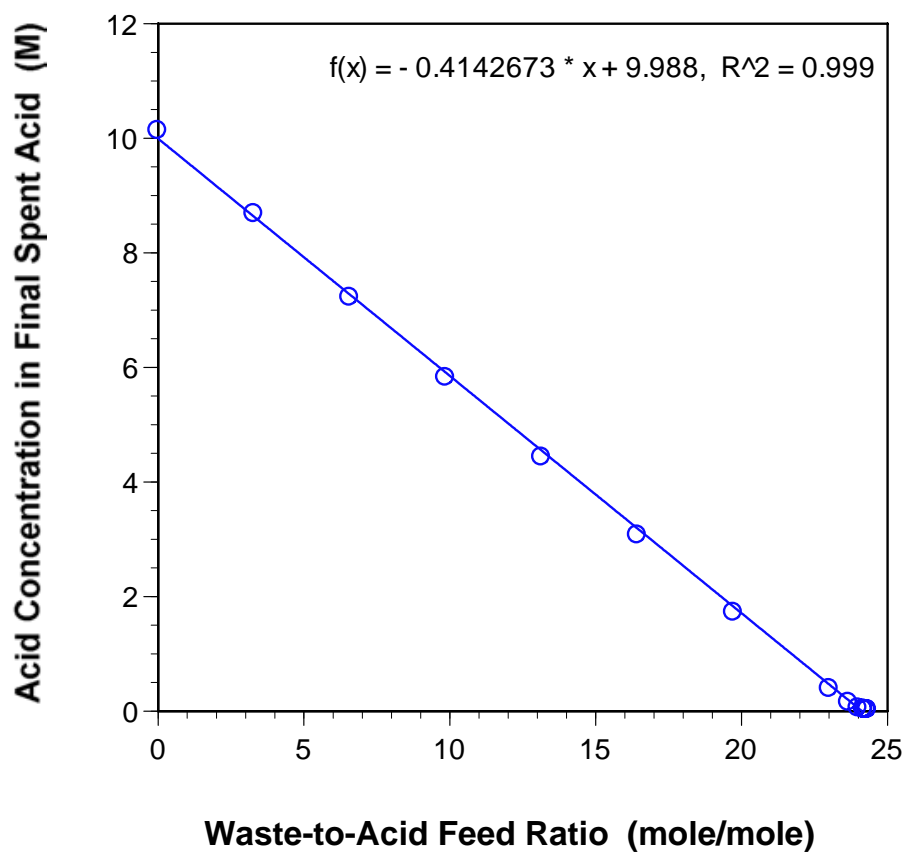

FIGURE 7. Acid Concentration in Final Spent Acid vs. Waste-to-Acid Feed Ratio. 
It is also seen in Table 7 that the maximum air emission of nitric acid occurs when the acid concentration in the final spent acid effluent from Stage 5 is the highest at the waste-to-acid feed ratio of zero or zero scale flow. This confirms the validity of the key basis of the hydraulic calculations made earlier that the maximum acid emission would occur when the fresh acid flows through the deposit-free header. In all the remaining cases of fouled header or nonzero scale flows, the calculated concentrations of nitric acid in the gas phase were at their maxima in Stage 1 and then gradually decreased to their final values in Stage 5 as more and more acid was consumed by the dissolving scale material. The model predicted no other pollutants to form beside nitric acid vapor.

Figure 8 shows the acid emission and the scaling tendencies of the three major salts expected to precipitate in the final spent acid effluent from Stage 5 (Stream 9) as a function of the acidity of Stream 9. The scaling tendency of a salt is defined as the ratio of the product of molar concentrations of constituent ions to its solubility product. So, when a solution is saturated with a particular salt, its scaling tendency would be unity. It is seen that the scaling tendencies of $\mathrm{NaNO}_{3}$ and $\mathrm{Fe}\left(\mathrm{NO}_{3}\right)_{3} \cdot 9 \mathrm{H}_{2} \mathrm{O}$ never approached the threshold value for all the cases considered in this study and, only at the highest waste-to-acid feed ratio of 24.33, traces of $\mathrm{Fe}(\mathrm{OH})_{3}$ were predicted to form in the spent acid. This means that the maximum quantity of scale material that could be dissolved in the nitric acid solution would be determined by the solubility of $\mathrm{Fe}(\mathrm{OH})_{3}$.

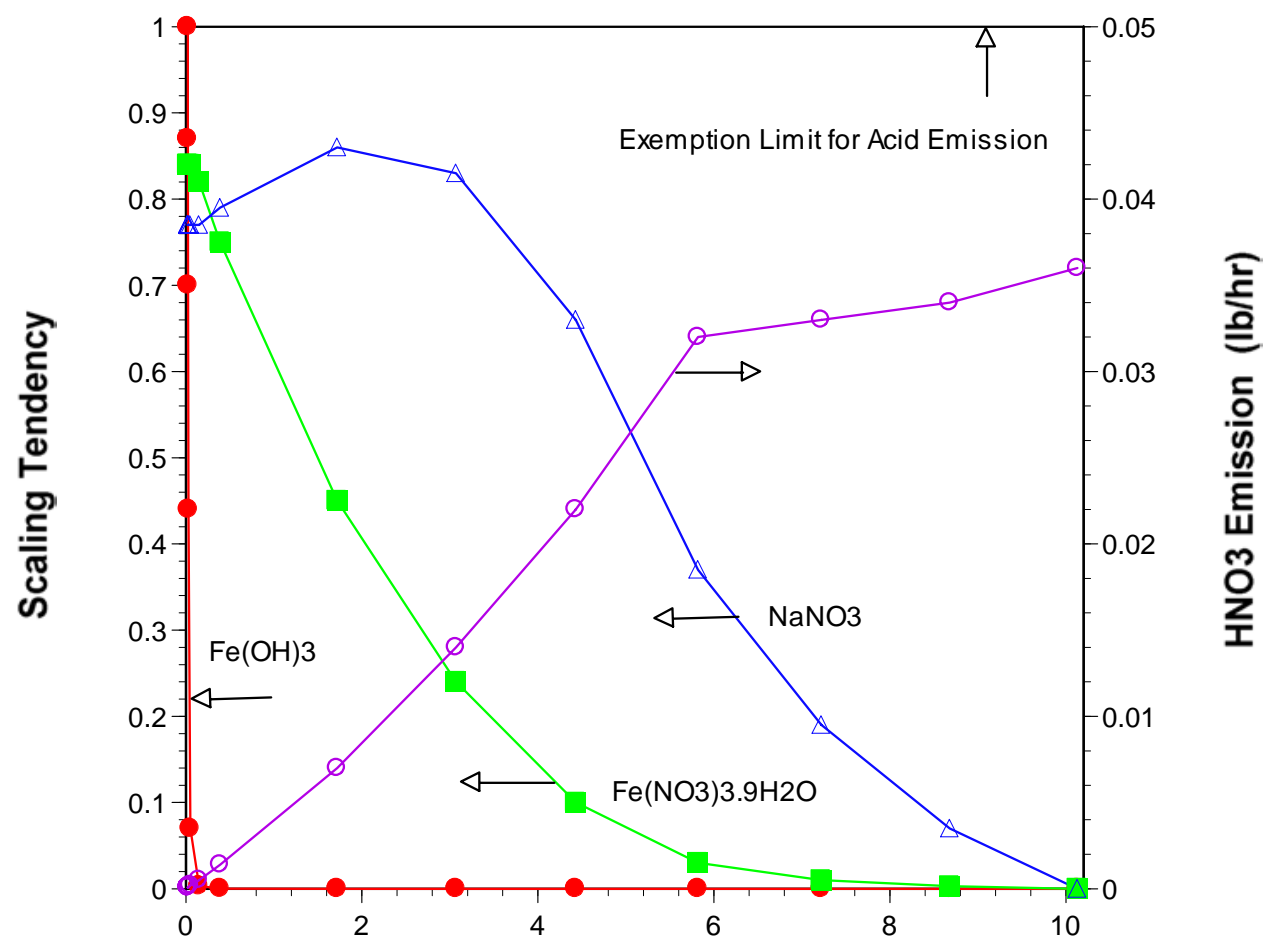

Acid Concentration in Final Spent Acid (M)

FIGURE 8. Acid Emission and Scaling Tendency vs. Acidity in Final Spent Acid. 


\section{CONCLUSION}

The worst-case air emission of nitric acid during the acid cleaning of the F-Canyon Waste Header \#2 was estimated to be $0.048 \mathrm{lb} / \mathrm{hr}$, which is just below the current exemption limit of $0.05 \mathrm{lb} / \mathrm{hr}$ for permit applications. This maximum air emission projection is conservative, since it was derived based on the worst-case scenario of ambient air flowing in the direction of the FTP-3 at its maximum possible rate and becoming fully equilibrated with the fresh nitric acid solution in the deposit-free waste header. As a result, it is concluded that there is no realistic probability that the nitric acid emission at the stack of the FPP-2/3 ventilation system ever exceeds the exemption limit. No other pollutants beside $\mathrm{HNO}_{3}$ were predicted to form as a result of the acid cleaning operation.

The ESP modeling of scale formation and dissolution chemistry predicted ferric hydroxide to be the primary constituent of the scale material. Also predicted to form in the composite FCAN-RW stream are the precipitates of sodium diuranate and mercuric oxide at one- and two-orders of magnitude lower molar concentrations than ferric hydroxide, respectively. The ESP model further confirmed that the air emission of nitric acid would be at its maximum when the fresh acid flows through the deposit-free waste header concurrently with ambient air. 


\section{REFERENCES}

1. Loftin, S. G., "F-Canyon Waste Compliance Plan for the Acid Flush of Waste Header \#2,” NMS-ETS-2001-00053, Revision 0, April 2, 2001.

2. Technical Task Request, HLE-TTR-2002-019, CSTE Support, January 23, 2002.

3. Martin, D. J., Private Communication, November 2002.

4. HLW Emergency Response Data and Waste Tank Status Data, N-ESR-G-00001, Rev. 99, March 28, 2001.

5. Martin, D. J., "Agitation of FPT-3 during Acid Flush of F-Canyon Waste Header \#2," WSRC-TR-2001-00192, Rev. 0, April 2, 2001.

6. White, D. F., Electronic Mail Communication, November 15, 2002.

7. Gohel, K., Private Communication, October 2002.

8. Flow of Fluids through Valves, Fittings, and Pipe, Technical Paper No. 410, Crane Co., Kings of Prussia, PA (1988).

9. Lockhart, R. W., and Martinelli, R. C., "Proposed Correlation of Data for Isothermal Two-Phase, Two-Component Flow in Pipes," Chem. Eng. Prog., 45, pp 39-48 (1949).

10. Perry's Chemical Engineers' Handbook, $7^{\text {th }}$ Ed., R. H. Perry and D. W. Green, Eds., McGraw-Hill, New York (1997).

11. Choi, A. S., "Air Emission Projections during 2H Evaporator Cleaning and Neutralization (U)," WSRC-TR-2000-00533, January 24, 2001.

12. Wallis, G. B., One-Dimensional Two-Phase Flow, McGraw-Hill, New York (1969).

13. ESP Software, http://www.olisystems.com/, OLI Systems, Inc., Morris Plains, NJ (2002).

14. Choi, A. S., "Physical Property Models of Concentrated Cesium Eluate Solutions," WSRC-TR-2002-00424, March 12, 2003.

15. Lange's Handbook of Chemistry, $11^{\text {th }}$ Ed., McGraw-Hill, N.Y., (1973) 


\section{APPENDIX A}

Sample Calculation \#1: Find the particle size whose terminal velocity equals the superficial gas velocity in the FPT-3 vapor space.

Data: Air flow rate through the FPT-3 vapor space $=96.5 \mathrm{cfm}$

Diameter of FPT-3 $=12 \mathrm{ft}$

Height of FPT-3 = $8 \mathrm{ft} 6$ in

Superficial gas velocity in the FPT-3 vapor space is:

$$
\begin{aligned}
V_{\text {gas }} & =\frac{96.5 \frac{f^{3}}{\min }}{\pi \frac{(12 f t)^{2}}{4}\left(60 \frac{\mathrm{sec}}{\min }\right)} \\
& =0.142 \mathrm{ft} / \mathrm{sec}
\end{aligned}
$$

The particle terminal velocity is calculated using the following equation: ${ }^{10}$

$$
u_{t}=\sqrt{\frac{2 g m_{p}\left(\rho_{p}-\rho\right)}{\rho \rho_{p} A_{p} C_{D}}}
$$

where $C_{D}$ is the drag coefficient, $m_{p}$ the particle mass, and $A_{p}$ the projected particle area in direction of motion. Assuming a spherical particle with diameter $d_{p}$, substitution of the appropriate data from Table 2 into Eq. (18) yields:

$$
\begin{aligned}
u_{t} & =\sqrt{\frac{(2)\left(32.2 \frac{f t}{\mathrm{sec}^{2}}\right)\left(\frac{\pi d_{p}^{3} \rho_{p}}{6}\right)(81.78-0.0716) \frac{l b_{m}}{f t^{3}}}{\left(0.0716 \frac{l b_{m}}{f t^{3}}\right) \rho_{p}\left(\frac{\pi d_{p}^{2}}{4}\right) C_{D}}} \\
& =221.35 \sqrt{\frac{d_{p}}{C_{D}}}
\end{aligned}
$$

Further substitution of $0.142 \mathrm{ft} / \mathrm{sec}$ for $u_{t}$ yields:

$$
d_{p}=4.1156 E-7 C_{D}
$$


The drag coefficient, $C_{D}$, is a function of particle Reynolds number. Therefore, the particle diameter must be solved by iteration. From Figure 6-61 in Reference 10, $d_{p}$ is estimated to be between 30 and $40 \mu \mathrm{m}$. So, let's assume $d_{p}=35 \mu \mathrm{m}$ or $0.0001148 \mathrm{ft}$. The particle Reynolds number is then calculated as:

$$
\begin{aligned}
\operatorname{Re}_{p} & =\frac{\rho v d_{p}}{\mu} \\
& =\frac{\left(0.0716 \frac{l b_{m}}{f t^{3}}\right)\left(0.142 \frac{f t}{\mathrm{sec}}\right)(0.0001148 f t)}{1.2633 E-5 \frac{l b_{m}}{f t . \mathrm{sec}}} \\
& =0.0924
\end{aligned}
$$

The drag coefficient is then calculated as:

$$
\begin{aligned}
C_{D} & =\operatorname{Re}_{p} \frac{4 g \mu\left(\rho_{p}-\rho\right)}{3 \rho^{2} u_{t}^{3}} \\
& =\frac{(0.0924)(4)\left(32.2 \frac{f t^{2}}{\mathrm{sec}}\right)\left(1.2633 E-5 \frac{l b_{m}}{f t . \mathrm{sec}}\right)(81.78-0.0716) \frac{l b_{m}}{f t^{3}}}{(3)\left(0.0716 \frac{l b_{m}}{f t^{3}}\right)^{2}\left(0.142 \frac{f t}{\mathrm{sec}}\right)^{3}} \\
& =279
\end{aligned}
$$

The particle diameter is then calculated from Eq. (19) as:

$$
\begin{aligned}
d_{p} & =(4.1156 E-7)(279) \\
& =0.0001148 \mathrm{ft}
\end{aligned}
$$

Therefore, we now have a converged solution at $d_{p}=0.0001148 \mathrm{ft}$ or $35 \mu \mathrm{m}$. 
Sample Calculation \#2: Find the minimum static pressure on the canyon side of the Waste Header \#2 necessary to maintain an air flow in the direction of the FPT-3.

The minimum canyon-side static pressure would occur when there is no frictional loss due to fluid flow in the waste header, i.e., $h_{L}=0$. Substitution of appropriate data from Table 2 into Eq. (9) yields:

$$
\begin{aligned}
h_{L} & =z_{1}-z_{2}+\frac{144}{\rho_{G}}\left(P_{1}-P_{2}\right) \\
0 & =43 f t+\frac{144 \frac{i n^{2}}{f t^{2}}}{0.0716 \frac{l b}{f t^{3}}}\left(P_{1}-P_{2}\right)
\end{aligned}
$$

Solve for the differential static pressure:

$$
\begin{aligned}
P_{1}-P_{2} & =-43 f t\left(\frac{144 \frac{i n^{2}}{f t^{2}}}{0.0716 \frac{l b}{f t^{3}}}\right)^{-1} \\
& =-0.0214 \frac{l b}{i n^{2}} \\
& =\left(-0.0214 \frac{l b}{i n^{2}}\right)\left(\frac{27.7 " w c}{\frac{l b}{i n^{2}}}\right) \\
& \approx-0.6 " w c
\end{aligned}
$$

The minimum canyon-side static pressure is then:

$$
\begin{aligned}
P_{1} & =-0.6 " w c+(-2 " w c) \\
& =-2.6 " w c
\end{aligned}
$$


Sample Calculation \#3: Determine the maximum air flow through the Waste Header \#2 following the calculational procedure outlined in Section 6.1.2.

1. Assume $\mathrm{X}=0.48$.

2. Read the liquid volume fraction, $R_{L}=0.15$, from Figure 3 .

3. Calculate the two-phase flow density by substituting appropriate data from Table 2 into Eq. (12):

$$
\begin{aligned}
\rho_{T P} & =\rho_{L} R_{L}+\rho_{G}\left(1-R_{L}\right) \\
& =\left(81.78 \frac{l b}{f t^{3}}\right)(0.15)+\left(0.0716 \frac{l b}{f t^{3}}\right)(1-0.15) \\
& =12.3279 \frac{l b}{f t^{3}}
\end{aligned}
$$

4. Calculate the two-phase total head loss using Eq. (9):

$$
\begin{aligned}
h_{L}^{T P} & =z_{1}-z_{2}+\frac{144}{\rho_{T P}}\left(P_{1}-P_{2}\right) \\
& =43 f t+\frac{144 \frac{i n^{2}}{f t^{2}}}{12.3279 \frac{l b}{f t^{3}}}\left(2^{\prime \prime} w c\right)\left(\frac{\frac{l b}{i n^{2}}}{27.7^{\prime \prime} w c}\right) \\
& =43.84 \mathrm{ft}
\end{aligned}
$$

5. Assume viscous and turbulent (V-T) flows for gas and liquid phases, respectively.

6. Read $Y_{G}=6$ from Figure 1 and calculate $Y_{L}$ from Eq. (7):

$$
\begin{aligned}
Y_{L} & =\frac{Y_{G}}{X^{2}} \\
& =\frac{6}{(0.48)^{2}} \\
& =26
\end{aligned}
$$


7. Calculate the total head losses for the gas and liquid phases using Eqs. (10) and (11):

$$
\begin{aligned}
& h_{L}^{G}=\frac{h_{L}^{T P}}{Y_{G}}=\frac{43.84}{6}=7.307 \\
& h_{L}^{L}=\frac{h_{L}^{T P}}{Y_{L}}=\frac{43.84}{26}=1.686
\end{aligned}
$$

8. Calculate the superficial velocity of each phase. For the gas-phase, substitution of appropriate data from Table 2 into Eq. (13) yields:

$$
\begin{aligned}
v_{G} & =\sqrt{\frac{2 g h_{L}^{G} D}{f L}} \\
& =\sqrt{\frac{(2)\left(32.2 \frac{f t}{\sec ^{2}}\right)(7.307 f t)(0.25567 f t)}{f(2,311 f t)}} \\
& =\sqrt{\frac{0.05206}{f}}
\end{aligned}
$$

Assume $f=0.03$ and calculate $v_{G}$ and $R e_{G}$.

$$
\begin{aligned}
v_{G} & =\sqrt{\frac{0.05206}{0.03}}=1.3173 \frac{f t}{\mathrm{sec}} \\
\operatorname{Re}_{G} & =\frac{\rho_{G} v_{G} D}{\mu_{G}} \\
& =\frac{\left(0.0716 \frac{l b_{m}}{f t^{3}}\right) v_{G}(0.25567 f t)}{1.2633 E-5 \frac{l b_{m}}{f t \mathrm{sec}}} \\
& =1,449 v_{G} \\
& =(1,449)\left(1.3173 \frac{\mathrm{ft}}{\mathrm{sec}}\right)=1,909
\end{aligned}
$$


Calculate $f$ by:

$$
f=\frac{64}{\operatorname{Re}_{G}}=\frac{64}{1,909}=0.034 \quad(\Delta=13.3 \%)
$$

Re-calculate $v_{G}, \operatorname{Re}_{G}$, and $f$ :

$$
\begin{aligned}
& v_{G}=\sqrt{\frac{0.05206}{0.034}}=1.2374 \frac{f t}{\mathrm{sec}} \\
& \operatorname{Re}_{G}=(1,449)\left(1.2374 \frac{f t}{\mathrm{sec}}\right)=1,793 \\
& f=\frac{64}{1,793}=0.0357 \quad(\Delta=5 \%)
\end{aligned}
$$

Re-calculate $v_{G}, \operatorname{Re}_{G}$, and $f$ :

$$
\begin{aligned}
& v_{G}=\sqrt{\frac{0.05206}{0.0357}}=1.208 \frac{f t}{\mathrm{sec}} \\
& \operatorname{Re}_{G}=(1,449)\left(1.208 \frac{f t}{\mathrm{sec}}\right)=1,750 \\
& f=\frac{64}{1,750}=0.0366 \quad(\Delta=2.5 \%)
\end{aligned}
$$

Re-calculate $v_{G}, \operatorname{Re}_{G}$, and $f$ :

$$
\begin{aligned}
v_{G} & =\sqrt{\frac{0.05206}{0.0366}}=1.193 \frac{f t}{\mathrm{sec}} \\
\operatorname{Re}_{G} & =(1,449)\left(1.193 \frac{f t}{\mathrm{sec}}\right)=1,729 \\
f & =\frac{64}{1,729}=0.0370 \quad(\Delta=1 \%)
\end{aligned}
$$

Re-calculate $v_{G}, \operatorname{Re}_{G}$, and $f$ :

$$
v_{G}=\sqrt{\frac{0.05206}{0.0370}}=1.186 \frac{\mathrm{ft}}{\mathrm{sec}}
$$




$$
\begin{gathered}
\operatorname{Re}_{G}=(1,449)\left(1.186 \frac{f t}{\mathrm{sec}}\right)=1,719 \\
f=\frac{64}{1,719}=0.03723 \quad(\Delta=0.6 \%)
\end{gathered}
$$

Re-calculate $v_{G}, \operatorname{Re}_{G}$, and $f$ :

$$
\begin{aligned}
& v_{G}=\sqrt{\frac{0.05206}{0.03723}}=1.182 \frac{f t}{\mathrm{sec}} \\
& \operatorname{Re}_{G}=(1,449)\left(1.182 \frac{\mathrm{ft}}{\mathrm{sec}}\right)=1,713 \\
& f=\frac{64}{1,713}=0.03736 \quad(\Delta=0.3 \%)
\end{aligned}
$$

So, we now have a converged solution at $v_{G}=1.182 \mathrm{ft} / \mathrm{sec}$.

For the liquid-phase, substitution of appropriate data from Table 2 into Eq. (13) yields:

$$
\begin{aligned}
v_{L} & =\sqrt{\frac{2 g h_{L}^{L} D}{f L}} \\
& =\sqrt{\frac{(2)\left(32.2 \frac{f t}{\sec ^{2}}\right)(1.686 f t)(0.25567 f t)}{f(2,311 f t)}} \\
& =\sqrt{\frac{0.012}{f}}
\end{aligned}
$$

Assume $f=0.02$ and calculate $v_{L}$ and $R e_{L}$.

$$
v_{L}=\sqrt{\frac{0.012}{0.02}}=0.775 \frac{\mathrm{ft}}{\mathrm{sec}}
$$




$$
\begin{aligned}
\operatorname{Re}_{L} & =\frac{\rho_{L} v_{L} D}{\mu_{L}} \\
& =\frac{\left(81.78 \frac{l b_{m}}{f t^{3}}\right) v_{L}(0.25567 f t)}{1.277 E-3 \frac{l b_{m}}{f t \mathrm{sec}}} \\
& =16,373 v_{L} \\
& =(16,373)\left(0.775 \frac{f t}{\mathrm{sec}}\right)=12,689
\end{aligned}
$$

$\operatorname{Read} f \approx 0.03$ from Figure A-24 in Reference 8.

Re-calculate $v_{L}$ and $\operatorname{Re}_{L}$ and re-estimate $f$.

$$
\begin{aligned}
& v_{L}=\sqrt{\frac{0.012}{0.03}}=0.632 \frac{f t}{\mathrm{sec}} \\
& \operatorname{Re}_{L}=(16,373)\left(0.632 \frac{\mathrm{ft}}{\mathrm{sec}}\right)=10,348 \\
& f \approx 0.031 \text { read from Figure } A-24 \quad(\Delta=3.3 \%)
\end{aligned}
$$

Re-calculate $v_{L}$ and $R e_{L}$ and re-estimate $f$.

$$
\begin{aligned}
& v_{L}=\sqrt{\frac{0.012}{0.031}}=0.622 \frac{f t}{\mathrm{sec}} \\
& \operatorname{Re}_{L}=(16,373)\left(0.622 \frac{f t}{\mathrm{sec}}\right)=10,184 \\
& f \approx 0.031 \text { read from Figure } A-24 \quad(\Delta \approx 0 \%)
\end{aligned}
$$

So, we now have a converged solution at $v_{L}=0.622 \mathrm{ft} / \mathrm{sec}$. 
9. The calculated Reynolds numbers for the gas and liquid phases $\left(\operatorname{Re}_{G}=1,713\right.$ and $\operatorname{Re}_{L}=$ 10,184) are consistent with the initial assumption that the gas and liquid phases are viscous and turbulent flows, respectively.

10. Determine the two-phase flow pattern using Figure 4.

It was assumed in this study that the physical properties of the gas phase saturated with the nitric acid vapor could be approximated by those of pure air. The validity of this assumption will be shown next.

The air that is in equilibrium with $50 \mathrm{wt} \%$ nitric acid solution has the following composition in terms of partial pressures: ${ }^{10}$

\begin{tabular}{lc}
\hline & Partial pressure $(\mathrm{mmHg})$ \\
\hline $\mathrm{HNO}_{3}$ & 0.8 \\
$\mathrm{H}_{2} \mathrm{O}$ & 19.0 \\
Air & 740.2 \\
\hline
\end{tabular}

The mean molecular weight of the saturated gas phase is calculated as:

$$
\begin{aligned}
\overline{M W} & =\left(\frac{0.8}{760}\right)(63)+\left(\frac{19}{760}\right)(18)+\left(\frac{740.2}{760}\right)(29) \\
& =28.76 \frac{\mathrm{g}}{\text { gmole }}
\end{aligned}
$$

The saturated gas-phase density at $35{ }^{\circ} \mathrm{C}$ is then calculated using the ideal gas law:

$$
\begin{aligned}
\rho_{G} & =\frac{P \overline{M W}}{R T} \\
& =\frac{(1 \mathrm{~atm})\left(28.76 \frac{\mathrm{g}}{\text { gmole }}\right)}{\left(0.0028978 \frac{\text { atm } \mathrm{ft}^{3}}{\text { gmole } K}\right)(308 \mathrm{~K})} \\
& =32.22 \frac{\mathrm{g}}{f t^{3}} \\
& =\left(32.22 \frac{\mathrm{g}}{\mathrm{ft}^{3}}\right)\left(\frac{\mathrm{lb}}{453.6 \mathrm{~g}}\right)=0.071 \frac{\mathrm{lb}}{\mathrm{ft}^{3}}
\end{aligned}
$$


It is noted that the difference between the calculated gas-phase density and that of the pure air assumed in this study, $0.0716 \mathrm{lb} / \mathrm{ft}^{3}$, is indeed small, i.e., less than $1 \%$.

Next, calculate the ratio of gas density to air density and the ratio of liquid density to water density:

$$
\begin{aligned}
\rho_{G}^{\prime}= & \frac{0.071 \frac{\mathrm{lb}}{f t^{3}}}{0.0716 \frac{\mathrm{lb}}{f t^{3}}}=0.992 \\
\rho_{L}^{\prime}= & \frac{1.31 \frac{\mathrm{g}}{\mathrm{ml}}}{1.0 \frac{\mathrm{g}}{\mathrm{ml}}}=1.31
\end{aligned}
$$

Using Eq. (14), the parameter $\lambda$ is calculated as:

$$
\begin{aligned}
\lambda & =\left(\rho_{G}^{\prime} \rho_{L}^{\prime}\right)^{1 / 2} \\
& =[(0.992)(1.31)]^{1 / 2}=1.14
\end{aligned}
$$

Using the data in Table 2, the ratio of liquid surface tension to water surface tension is calculated as:

$$
\begin{aligned}
\sigma^{\prime} & =\frac{\sigma_{L}}{\sigma_{H 2 O}} \\
& =\frac{0.067858 \frac{\mathrm{N}}{\mathrm{m}}}{0.073 \frac{\mathrm{N}}{\mathrm{m}}}=0.93
\end{aligned}
$$

The ratio of liquid viscosity to water viscosity is calculated as:

$$
\begin{aligned}
\mu_{L}^{\prime} & =\frac{\mu_{L}}{\mu_{H 2 O}} \\
& =\frac{1.9 c P}{1.0 c P}=1.9
\end{aligned}
$$

Using Eq. (15), the parameter $\psi$ is then calculated as: 


$$
\begin{aligned}
\psi & =\frac{1}{\sigma^{\prime}}\left[\frac{\mu_{L}^{\prime}}{\left(\rho_{L}^{\prime}\right)^{2}}\right]^{1 / 3} \\
& =\frac{1}{0.93}\left[\frac{1.9}{(1.31)^{2}}\right]^{1 / 3}=1.112
\end{aligned}
$$

Next, estimate the gas and liquid mass fluxes as follows:

$$
\begin{aligned}
G_{G} & =v_{G} \rho_{G} \\
& =\left(1.182 \frac{f t}{\mathrm{sec}}\right)\left(0.0716 \frac{\mathrm{lb}}{f t^{3}}\right)=0.085 \frac{\mathrm{lb}}{f t^{2} \mathrm{sec}} \\
G_{L} & =v_{L} \rho_{L} \\
& =\left(0.622 \frac{\mathrm{ft}}{\mathrm{sec}}\right)\left(81.78 \frac{\mathrm{lb}}{\mathrm{ft}^{3}}\right)=50.87 \frac{\mathrm{lb}}{\mathrm{ft}^{2} \mathrm{sec}}
\end{aligned}
$$

Finally, estimate the values of the following parameters for Figure 4.

$$
\begin{aligned}
& \frac{G_{G}}{\lambda}=\frac{0.085 \frac{l b}{f t^{2} \mathrm{sec}}}{1.14}=0.075 \frac{\mathrm{lb}}{f t^{2} \mathrm{sec}} \\
& \frac{G_{L} \lambda \psi}{G_{G}}=\frac{\left(50.87 \frac{\mathrm{lb}}{f t^{2} \mathrm{sec}}\right)(1.14)(1.112)}{0.085 \frac{l b}{f t^{2} \mathrm{sec}}}=759
\end{aligned}
$$

By locating the coordinates $(759,0.075)$ in Figure 4, it can be seen that the two-phase flow considered in this study falls in the "plug" flow region. 


\section{APPENDIX B}

\section{ESP Model Output}

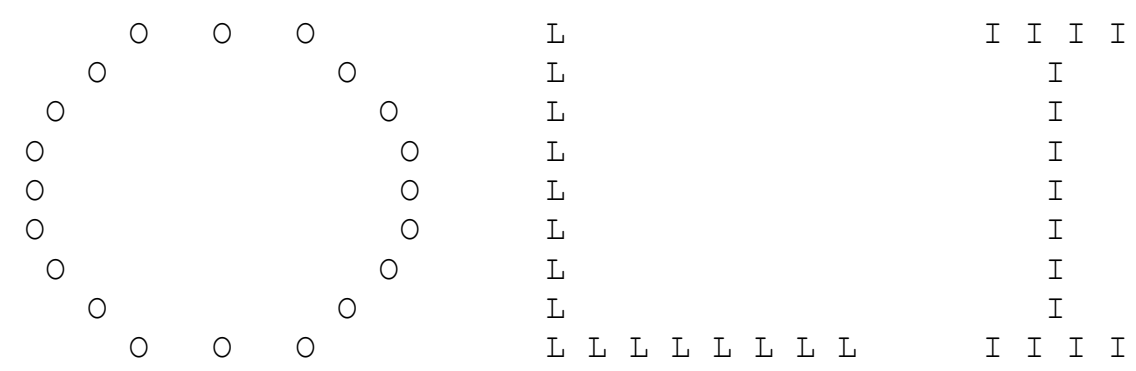

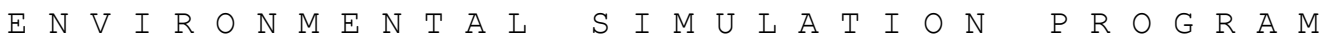
$\mathrm{V}-6.6$ October 1,2002

PROCESS: FCANRWA

CHEMISTRY MODEL: F-WASTE

THIS FILE NAME: FCANRWA.LIS

DATE: $12 / 14 / 2002$

\section{$L-M$ Parameter $X=0.48$}

Waste-to-Acid Molar Flow Ratio $=16.4$ 


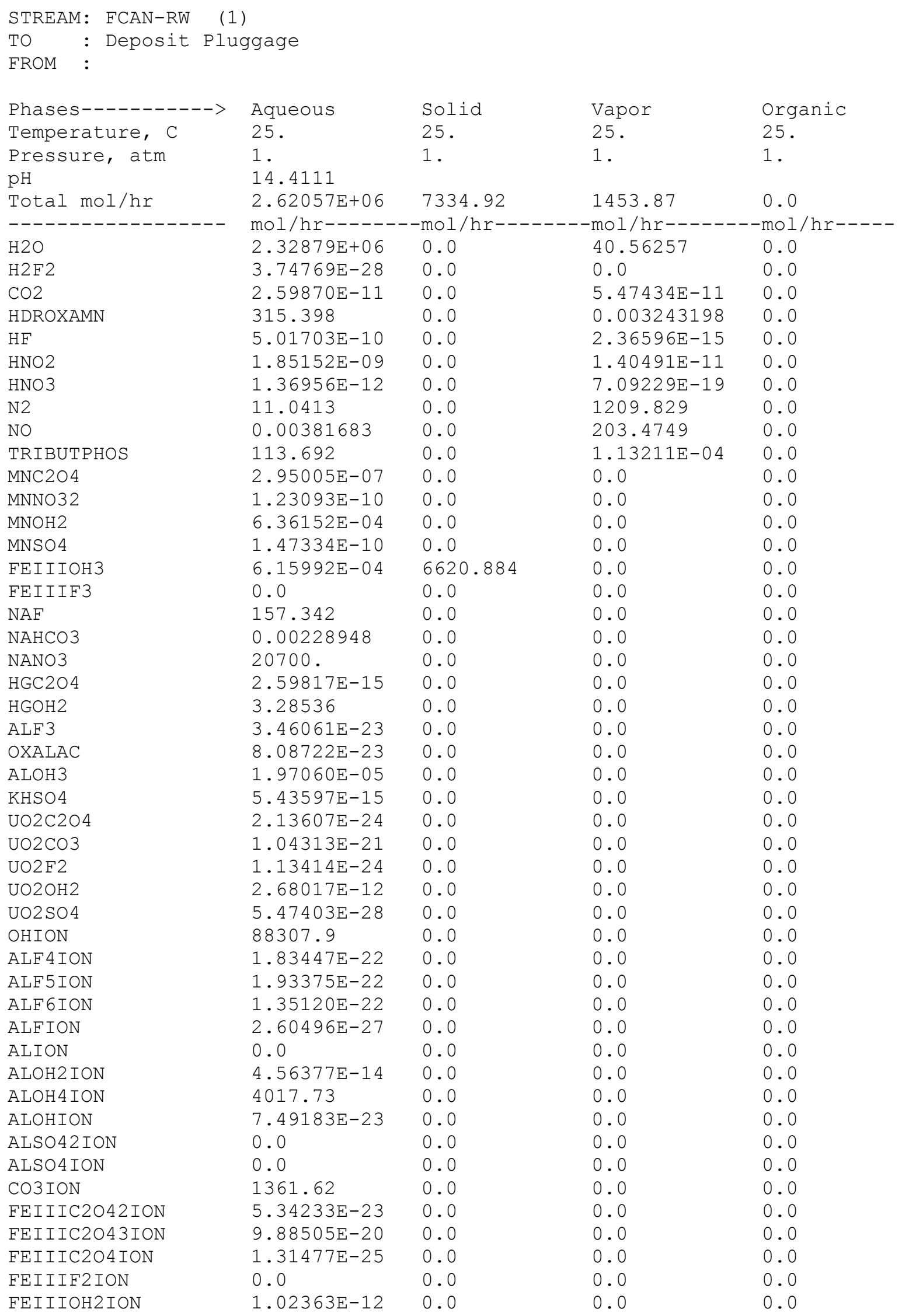




\begin{tabular}{|c|c|c|c|c|}
\hline FEIIIOH4ION & 154.128 & 0.0 & 0.0 & 0.0 \\
\hline FEIIIOHION & $4.20103 E-22$ & 0.0 & 0.0 & 0.0 \\
\hline FION & 348.539 & 0.0 & 0.0 & 0.0 \\
\hline HCO3ION & 0.0104388 & 0.0 & 0.0 & 0.0 \\
\hline HF2 ION & $2.02162 \mathrm{E}-12$ & 0.0 & 0.0 & 0.0 \\
\hline HGFION & $1.89483 \mathrm{E}-23$ & 0.0 & 0.0 & 0.0 \\
\hline HGION & $7.99776 \mathrm{E}-22$ & 0.0 & 0.0 & 0.0 \\
\hline $\mathrm{HGOH} 3 \mathrm{ION}$ & 3.84206 & 0.0 & 0.0 & 0.0 \\
\hline HGOHION & $2.76713 \mathrm{E}-11$ & 0.0 & 0.0 & 0.0 \\
\hline HHDRAMION & $3.60658 E-06$ & 0.0 & 0.0 & 0.0 \\
\hline HION & $3.41150 \mathrm{E}-10$ & 0.0 & 0.0 & 0.0 \\
\hline HOXALATION & $3.04595 E-09$ & 0.0 & 0.0 & 0.0 \\
\hline HSO 4 ION & $7.07419 \mathrm{E}-11$ & 0.0 & 0.0 & 0.0 \\
\hline KION & 878.946 & 0.0 & 0.0 & 0.0 \\
\hline KSO 4 ION & 25.4112 & 0.0 & 0.0 & 0.0 \\
\hline MNC2O42ION & $4.85603 E-09$ & 0.0 & 0.0 & 0.0 \\
\hline MNC2O43ION & $1.34059 \mathrm{E}-07$ & 0.0 & 0.0 & 0.0 \\
\hline MNION & $2.46419 E-08$ & 0.0 & 0.0 & 0.0 \\
\hline MNNO3ION & $3.56375 \mathrm{E}-10$ & 0.0 & 0.0 & 0.0 \\
\hline MNOH3ION & 0.163639 & 0.0 & 0.0 & 0.0 \\
\hline MNOH 4 ION & 11.6105 & 0.0 & 0.0 & 0.0 \\
\hline MNOHION & $7.28705 \mathrm{E}-06$ & 0.0 & 0.0 & 0.0 \\
\hline MNVI I O 4 ION & 383.197 & 0.0 & 0.0 & 0.0 \\
\hline NA2FION & 15.2792 & 0.0 & 0.0 & 0.0 \\
\hline NACO3ION & 637.898 & 0.0 & 0.0 & 0.0 \\
\hline NAION & 136699. & 0.0 & 0.0 & 0.0 \\
\hline NASO 4 ION & 4762.44 & 0.0 & 0.0 & 0.0 \\
\hline NO2 ION & 1111.78 & 0.0 & 0.0 & 0.0 \\
\hline NO3ION & 28424.8 & 0.0 & 0.0 & 0.0 \\
\hline ALF2ION & $1.98669 \mathrm{E}-24$ & 0.0 & 0.0 & 0.0 \\
\hline OXALATION & 672.848 & 0.0 & 0.0 & 0.0 \\
\hline SO4 ION & 2661.66 & 0.0 & 0.0 & 0.0 \\
\hline UO2C2O42ION & $5.29881 \mathrm{E}-22$ & 0.0 & 0.0 & 0.0 \\
\hline UO2C2O43ION & $5.64458 \mathrm{E}-20$ & 0.0 & 0.0 & 0.0 \\
\hline UO2C032ION & $1.38754 \mathrm{E}-15$ & 0.0 & 0.0 & 0.0 \\
\hline UO2C033ION & $8.57349 \mathrm{E}-10$ & 0.0 & 0.0 & 0.0 \\
\hline UO2F3ION & $4.11077 \mathrm{E}-24$ & 0.0 & 0.0 & 0.0 \\
\hline UO2F 4 ION & $1.14651 \mathrm{E}-24$ & 0.0 & 0.0 & 0.0 \\
\hline UO2FION & $2.40941 \mathrm{E}-25$ & 0.0 & 0.0 & 0.0 \\
\hline UO2 ION & $7.78132 \mathrm{E}-28$ & 0.0 & 0.0 & 0.0 \\
\hline UO2OHION & $5.61925 E-19$ & 0.0 & 0.0 & 0.0 \\
\hline UO2SO $42 \mathrm{ION}$ & $6.71777 \mathrm{E}-28$ & 0.0 & 0.0 & 0.0 \\
\hline NA2U2O 7 & 0.0 & 592.0944 & 0.0 & 0.0 \\
\hline HGO & 0.0 & 121.9419 & 0.0 & 0.0 \\
\hline & $=============$ & $=============$ & $=============$ & $=====$ \\
\hline Total g/hr & $5.17308 E+07$ & $1.10939 \mathrm{E}+06$ & 40727.8 & 0.0 \\
\hline Volume, L/hr & 44773.8 & 210.474 & 35562.9 & 0.0 \\
\hline Enthalpy, cal/hr & $-1.79371 \mathrm{E}+11$ & $-1.78844 \mathrm{E}+09$ & $2.09173 \mathrm{E}+06$ & 0.0 \\
\hline Density, g/L & 1155.38 & 5270.89 & 1.14523 & \\
\hline Vapor fraction & 0.0 & 0.0 & 1 & 0.0 \\
\hline Solid fraction & 0.0 & 1. & 0.0 & 0.0 \\
\hline Osmotic Pres, atm & 178.577 & & & \\
\hline $\mathrm{E}-\mathrm{Con}, 1 / \mathrm{ohm}-\mathrm{cm}$ & 0.252967 & & & \\
\hline E-Con, cm2/ohm-mol & 68.396 & & & \\
\hline Abs Visc, CP & 1.82987 & & & \\
\hline Rel Visc & 2.05438 & & & \\
\hline Ionic Strength & 3.39186 & & & \\
\hline
\end{tabular}




\begin{tabular}{|c|c|c|c|c|}
\hline \multicolumn{5}{|c|}{ TO : Deposit Pluggage } \\
\hline Phases-----------> & Aqueous & Solid & Vapor & Organic \\
\hline Temperature, C & 25. & 25 . & 25 . & 25 . \\
\hline $\begin{array}{l}\text { Pressure, atm } \\
\mathrm{pH}\end{array}$ & $\begin{array}{l}1 . \\
0.0\end{array}$ & 1 . & 1 . & 1 . \\
\hline Total mol/hr & 0.0 & 0.0 & 245 . & 0.0 \\
\hline------------------ & $\mathrm{mol} / \mathrm{hr}-----1$ & $---\operatorname{mol} / \mathrm{hr}-----1$ & $---\operatorname{mol} / \mathrm{hr}------$ & $--\operatorname{mol} / \mathrm{hr}-----$ \\
\hline $\mathrm{H} 2 \mathrm{O}$ & 0.0 & 0.0 & 1.829897 & 0.0 \\
\hline $\mathrm{CO} 2$ & 0.0 & 0.0 & 0.08035988 & 0.0 \\
\hline N2 & 0.0 & 0.0 & 192.1457 & 0.0 \\
\hline 02 & 0.0 & 0.0 & 50.94403 & 0.0 \\
\hline & $==========$ & $============$ & $============$ & $============$ \\
\hline Total g/hr & 0.0 & 0.0 & 7049.31 & 0.0 \\
\hline Volume, L/hr & 0.0 & 0.0 & 5993.07 & 0.0 \\
\hline $\begin{array}{l}\text { Enthalpy, cal/hr } \\
\text { Density, g/L }\end{array}$ & 0.0 & 0.0 & $\begin{array}{l}-1.13733 \mathrm{E}+05 \\
1.17624\end{array}$ & 0.0 \\
\hline Vapor fraction & 0.0 & 0.0 & 1 . & 0.0 \\
\hline Solid fraction & 0.0 & 0.0 & 0.0 & 0.0 \\
\hline Osmotic Pres, atm & 0.0 & & & \\
\hline E-Con, 1/ohm-cm & 0.0 & & & \\
\hline E-Con, cm2/ohm-mol & 0.0 & & & \\
\hline Abs Visc, CP & 0.0 & & & \\
\hline Rel Visc & 0.0 & & & \\
\hline Ionic Strength & 0.0 & & & \\
\hline
\end{tabular}




\begin{tabular}{|c|c|c|c|c|}
\hline \multicolumn{5}{|c|}{ FROM : Deposit Pluggage } \\
\hline Phases-----------> & Aqueous & Solid & Vapor & Organic \\
\hline Temperature, C & 35 . & 35 . & 35 & 35 . \\
\hline Pressure, atm & 1. & 1. & 1. & 1. \\
\hline $\mathrm{pH}$ & 0.0 & & & \\
\hline Total mol/hr & 0.0 & 0.0 & 1743.96 & 0.0 \\
\hline \multicolumn{5}{|l|}{------------------} \\
\hline $\mathrm{H} 2 \mathrm{O}$ & 0.0 & 0.0 & 86.64208 & 0.0 \\
\hline $\mathrm{H} 2 \mathrm{~F} 2$ & 0.0 & 0.0 & 0.0 & 0.0 \\
\hline $\mathrm{CO} 2$ & 0.0 & 0.0 & $3.48965 \mathrm{E}-10$ & 0.0 \\
\hline HDROXAMN & 0.0 & 0.0 & 0.007478356 & 0.0 \\
\hline $\mathrm{HF}$ & 0.0 & 0.0 & $1.26206 \mathrm{E}-14$ & 0.0 \\
\hline HNO2 & 0.0 & 0.0 & $5.35824 \mathrm{E}-11$ & 0.0 \\
\hline HNO3 & 0.0 & 0.0 & $6.14453 \mathrm{E}-18$ & 0.0 \\
\hline N2 & 0.0 & 0.0 & 1403.533 & 0.0 \\
\hline NO & 0.0 & 0.0 & 203.4774 & 0.0 \\
\hline $\mathrm{O} 2$ & 0.0 & 0.0 & 50.29961 & 0.0 \\
\hline \multirow[t]{2}{*}{ TRIBUTPHOS } & 0.0 & 0.0 & $4.15665 \mathrm{E}-04$ & 0.0 \\
\hline & $===========$ & $===========$ & $===========$ & $============$ \\
\hline Total g/hr & 0.0 & 0.0 & 48593.9 & 0.0 \\
\hline Volume, L/hr & 0.0 & 0.0 & 44086.9 & 0.0 \\
\hline $\begin{array}{l}\text { Enthalpy, cal/hr } \\
\text { Density, g/L }\end{array}$ & 0.0 & 0.0 & $\begin{array}{l}-4.49563 E+05 \\
1.10223\end{array}$ & 0.0 \\
\hline Vapor fraction & 0.0 & 0.0 & 1. & 0.0 \\
\hline Solid fraction & 0.0 & 0.0 & 0.0 & 0.0 \\
\hline Osmotic Pres, atm & 0.0 & & & \\
\hline E-Con, 1/ohm-cm & 0.0 & & & \\
\hline E-Con, cm2/ohm-mol & 0.0 & & & \\
\hline Abs Visc, cP & 0.0 & & & \\
\hline Rel Visc & 0.0 & & & \\
\hline Ionic Strength & 0.0 & & & \\
\hline
\end{tabular}




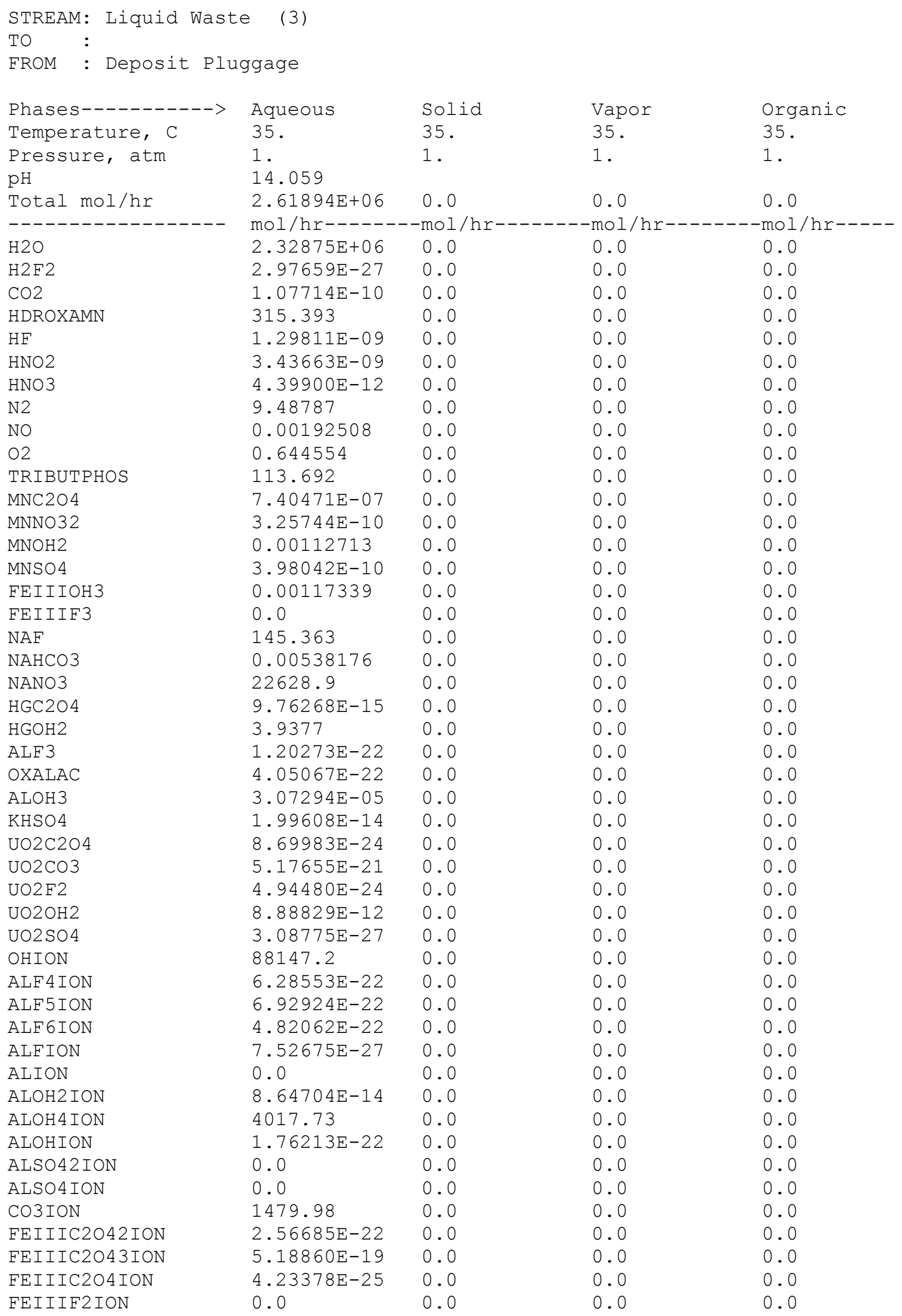




\begin{tabular}{|c|c|c|c|c|}
\hline EEIIIFION & 0.0 & 0.0 & 0.0 & 0.0 \\
\hline FEIIIOH2ION & $2.79407 \mathrm{E}-12$ & 0.0 & 0.0 & 0.0 \\
\hline FEIIIOH 4ION & 314.4 & 0.0 & 0.0 & 0.0 \\
\hline FEIIIOHION & $1.63545 \mathrm{E}-21$ & 0.0 & 0.0 & 0.0 \\
\hline FION & 360.426 & 0.0 & 0.0 & 0.0 \\
\hline HCO3ION & 0.0214971 & 0.0 & 0.0 & 0.0 \\
\hline HF2ION & $5.46415 \mathrm{E}-12$ & 0.0 & 0.0 & 0.0 \\
\hline HGFION & $8.07923 E-23$ & 0.0 & 0.0 & 0.0 \\
\hline HGION & $3.01431 \mathrm{E}-21$ & 0.0 & 0.0 & 0.0 \\
\hline HGOH 3 ION & 4.18188 & 0.0 & 0.0 & 0.0 \\
\hline HGOHION & $6.28617 \mathrm{E}-11$ & 0.0 & 0.0 & 0.0 \\
\hline HHDRAMION & $4.91788 \mathrm{E}-06$ & 0.0 & 0.0 & 0.0 \\
\hline HION & $8.14025 \mathrm{E}-10$ & 0.0 & 0.0 & 0.0 \\
\hline HOXALATION & $6.46722 \mathrm{E}-09$ & 0.0 & 0.0 & 0.0 \\
\hline HSO 4 ION & $2.25836 \mathrm{E}-10$ & 0.0 & 0.0 & 0.0 \\
\hline KION & 876.413 & 0.0 & 0.0 & 0.0 \\
\hline KSO 4 ION & 27.9441 & 0.0 & 0.0 & 0.0 \\
\hline MNC2O42ION & $9.02008 \mathrm{E}-09$ & 0.0 & 0.0 & 0.0 \\
\hline MNC2O43ION & $3.59684 \mathrm{E}-07$ & 0.0 & 0.0 & 0.0 \\
\hline MNION & $5.52577 \mathrm{E}-08$ & 0.0 & 0.0 & 0.0 \\
\hline MNNO3ION & $9.02077 \mathrm{E}-10$ & 0.0 & 0.0 & 0.0 \\
\hline MNOH 3 ION & 0.226854 & 0.0 & 0.0 & 0.0 \\
\hline $\mathrm{MNOH} 4 \mathrm{ION}$ & 11.5468 & 0.0 & 0.0 & 0.0 \\
\hline MNOHION & $1.69607 \mathrm{E}-05$ & 0.0 & 0.0 & 0.0 \\
\hline MNVI IO 4 ION & 383.197 & 0.0 & 0.0 & 0.0 \\
\hline NA2FION & 15.372 & 0.0 & 0.0 & 0.0 \\
\hline NACO3ION & 519.6 & 0.0 & 0.0 & 0.0 \\
\hline NAION & 135115 . & 0.0 & 0.0 & 0.0 \\
\hline NASO 4 ION & 4547.89 & 0.0 & 0.0 & 0.0 \\
\hline NO2 ION & 1111.78 & 0.0 & 0.0 & 0.0 \\
\hline NO3ION & 26496 . & 0.0 & 0.0 & 0.0 \\
\hline ALF2ION & $6.20473 E-24$ & 0.0 & 0.0 & 0.0 \\
\hline OXALATION & 672.848 & 0.0 & 0.0 & 0.0 \\
\hline SO4ION & 2873.68 & 0.0 & 0.0 & 0.0 \\
\hline $\mathrm{UO} 2 \mathrm{C} 2 \mathrm{O} 42 \mathrm{ION}$ & $5.07348 \mathrm{E}-22$ & 0.0 & 0.0 & 0.0 \\
\hline UO2C2O43ION & $2.65460 \mathrm{E}-19$ & 0.0 & 0.0 & 0.0 \\
\hline UO2CO32ION & $9.41952 \mathrm{E}-15$ & 0.0 & 0.0 & 0.0 \\
\hline UO2CO33ION & $3.50937 \mathrm{E}-09$ & 0.0 & 0.0 & 0.0 \\
\hline UO2F3ION & $1.93390 \mathrm{E}-23$ & 0.0 & 0.0 & 0.0 \\
\hline $\mathrm{UO} 2 \mathrm{~F} 4 \mathrm{ION}$ & $5.56750 \mathrm{E}-24$ & 0.0 & 0.0 & 0.0 \\
\hline UO2FION & $1.04130 \mathrm{E}-24$ & 0.0 & 0.0 & 0.0 \\
\hline UO2ION & $3.28983 E-27$ & 0.0 & 0.0 & 0.0 \\
\hline UO2OHION & $1.84710 \mathrm{E}-18$ & 0.0 & 0.0 & 0.0 \\
\hline UO2SO 42 ION & $5.20816 \mathrm{E}-27$ & 0.0 & 0.0 & 0.0 \\
\hline & $=============$ & $=============$ & $===========$ & $=====$ \\
\hline Total g/hr & $5.17473 \mathrm{E}+07$ & 0.0 & 0.0 & 0.0 \\
\hline Volume, L/hr & 44917.9 & 0.0 & 0.0 & 0.0 \\
\hline Enthalpy, cal/hr & $-1.78981 \mathrm{E}+11$ & 0.0 & 0.0 & 0.0 \\
\hline Density, g/L & 1152.04 & & & \\
\hline Vapor fraction & 0.0 & 0.0 & 0.0 & 0.0 \\
\hline Solid fraction & 0.0 & 0.0 & 0.0 & 0.0 \\
\hline Osmotic Pres, atm & 177.755 & & & \\
\hline $\mathrm{E}-\mathrm{Con}, 1 / \mathrm{ohm}-\mathrm{cm}$ & 0.301453 & & & \\
\hline E-Con, cm2/ohm-mol & 58.1955 & & & \\
\hline Abs Visc, $C P$ & 1.47454 & & & \\
\hline Rel Visc & 2.04788 & & & \\
\hline Ionic Strength & 3.36198 & & & \\
\hline
\end{tabular}




\begin{tabular}{|c|c|c|c|c|}
\hline \multicolumn{2}{|c|}{$\begin{array}{l}\text { STREAM: } \text { Pluggage }(5) \\
\text { TO : Split Pluggage_1 }\end{array}$} & & & \\
\hline Phases-----------> & Aqueous & Solid & Vapor & Organic \\
\hline Temperature, C & 35 . & 35 . & 35. & 35. \\
\hline $\begin{array}{l}\text { Pressure, atm } \\
\mathrm{pH}\end{array}$ & $\begin{array}{l}1 . \\
0.0\end{array}$ & 1 . & 1. & 1 . \\
\hline Total mol/hr & 0.0 & 7173.66 & 0.0 & 0.0 \\
\hline--------------- & $\mathrm{mol} / \mathrm{hr}----$ & $---\operatorname{mol} / \mathrm{hr}----1$ & $--\operatorname{mol} / \mathrm{hr}----$ & $---\operatorname{mol} / \mathrm{hr}-----$ \\
\hline FEIIIOH3 & 0.0 & 6460.615 & 0.0 & 0.0 \\
\hline NA2U2O 7 & 0.0 & 592.0954 & 0.0 & 0.0 \\
\hline $\mathrm{HGO}$ & $\begin{aligned} & 0.0 \\
== & =========\end{aligned}$ & $\begin{aligned} & 120.9501 \\
&============\end{aligned}$ & $\begin{aligned} & 0.0 \\
== & =========\end{aligned}$ & $\begin{aligned} & 0.0 \\
== & =========\end{aligned}$ \\
\hline Total g/hr & 0.0 & $1.09204 \mathrm{E}+06$ & 0.0 & 0.0 \\
\hline Volume, L/hr & 0.0 & 205.417 & 0.0 & 0.0 \\
\hline $\begin{array}{l}\text { Enthalpy, cal/hr } \\
\text { Density, g/L }\end{array}$ & 0.0 & $\begin{array}{l}-1.75400 \mathrm{E}+09 \\
5316.22\end{array}$ & 0.0 & 0.0 \\
\hline Vapor fraction & 0.0 & 0.0 & 0.0 & 0.0 \\
\hline Solid fraction & 0.0 & 1. & 0.0 & 0.0 \\
\hline Osmotic Pres, atm & 0.0 & & & \\
\hline E-Con, $1 /$ ohm-cm & 0.0 & & & \\
\hline E-Con, cm2/ohm-mol & 0.0 & & & \\
\hline Abs Visc, $c P$ & 0.0 & & & \\
\hline Rel Visc & 0.0 & & & \\
\hline Ionic Strength & 0.0 & & & \\
\hline
\end{tabular}




\begin{tabular}{|c|c|c|c|c|}
\hline \multicolumn{5}{|c|}{$\begin{array}{l}\text { STREAM: Pluggage_1 } \\
\text { TO : }{ }^{1} \text { Dissolver_1 }\end{array}$} \\
\hline Phases-----------> & Aqueous & Solid & Vapor & Organic \\
\hline Temperature, C & 35 . & 35 . & 35 . & 35. \\
\hline $\begin{array}{l}\text { Pressure, atm } \\
\mathrm{pH}\end{array}$ & $\begin{array}{l}1 . \\
0.0\end{array}$ & 1. & 1 . & 1 . \\
\hline Total mol/hr & 0.0 & 1434.73 & 0.0 & 0.0 \\
\hline------------------ & $\operatorname{mol} / \mathrm{hr}-----1$ & $---\operatorname{mol} / \mathrm{hr}------$ & $--\operatorname{mol} / \mathrm{hr}------$ & $---\operatorname{mol} / \mathrm{hr}-----$ \\
\hline FEIIIOH3 & 0.0 & 1292.121 & 0.0 & 0.0 \\
\hline NA2U2O 7 & 0.0 & 118.4191 & 0.0 & 0.0 \\
\hline $\mathrm{HGO}$ & $\begin{aligned} & 0.0 \\
== & =========\end{aligned}$ & $\begin{aligned} & 24.18992 \\
== & =========\end{aligned}$ & $\begin{aligned} & 0.0 \\
== & ==========\end{aligned}$ & $\begin{aligned} & 0.0 \\
== & ==========\end{aligned}$ \\
\hline Total g/hr & 0.0 & 218409 . & 0.0 & 0.0 \\
\hline Volume, L/hr & 0.0 & 41.0834 & 0.0 & 0.0 \\
\hline $\begin{array}{l}\text { Enthalpy, cal/hr } \\
\text { Density, g/L }\end{array}$ & 0.0 & $\begin{array}{l}-3.50799 \mathrm{E}+08 \\
5316.22\end{array}$ & 0.0 & 0.0 \\
\hline Vapor fraction & 0.0 & 0.0 & 0.0 & 0.0 \\
\hline Solid fraction & 0.0 & 1. & 0.0 & 0.0 \\
\hline Osmotic Pres, atm & 0.0 & & & \\
\hline E-Con, $1 /$ ohm-cm & 0.0 & & & \\
\hline E-Con, cm2/ohm-mol & 0.0 & & & \\
\hline Abs Visc, cP & 0.0 & & & \\
\hline Rel Visc & 0.0 & & & \\
\hline Ionic Strength & 0.0 & & & \\
\hline
\end{tabular}




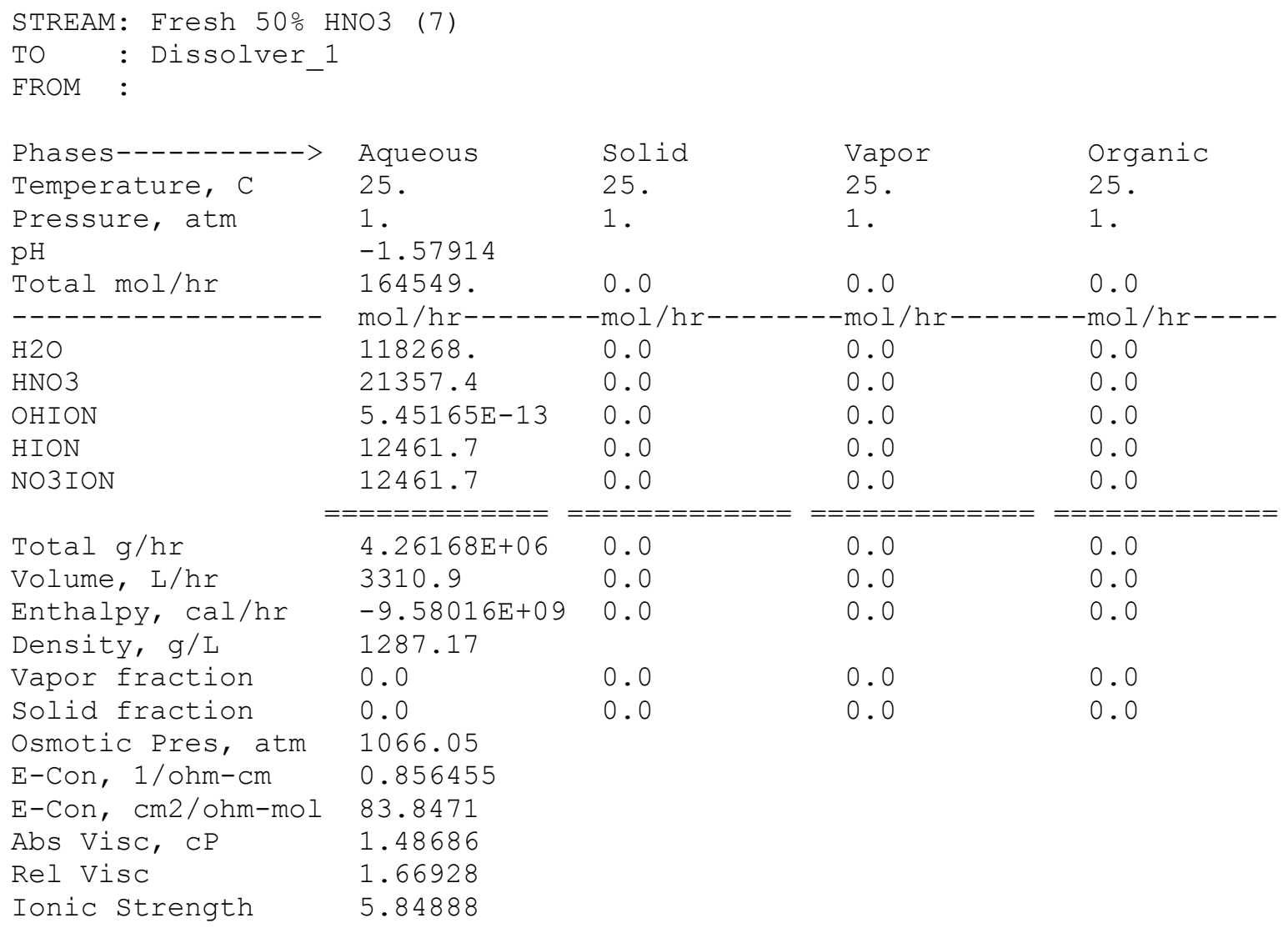




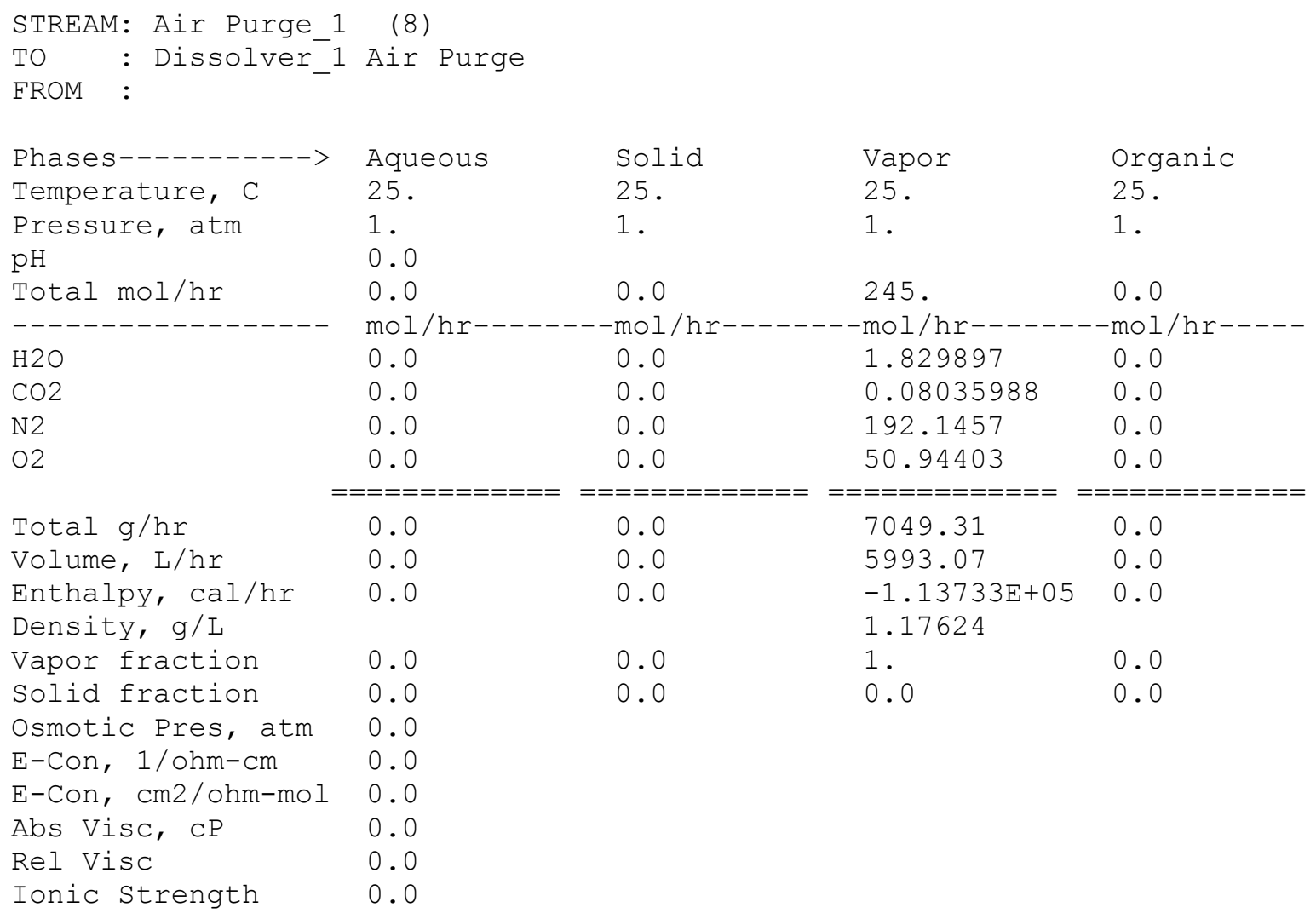




\begin{tabular}{|c|c|c|c|c|}
\hline STREAM: Dissolver 5 & out & & & \\
\hline TO: Dissolver_5 & Air Purge & & & \\
\hline FROM : Dissolver_5 & & & & \\
\hline Phases-----------> & Aqueous & Solid & Vapor & Organic \\
\hline Temperature, C & 35 & 35 . & 35 . & 35 . \\
\hline $\begin{array}{l}\text { Pressure, atm } \\
\mathrm{pH}\end{array}$ & $\begin{array}{l}1 . \\
-0.83866\end{array}$ & 1 & 1 & 1. \\
\hline Total mol/hr & 177045 & 0.0 & 0.0 & 0.0 \\
\hline $\begin{array}{l}------------------ \\
---\end{array}$ & $\operatorname{mol} / \mathrm{hr}------$ & $-\mathrm{mol} / \mathrm{hr}------$ & $-\operatorname{mol} / \mathrm{hr}-------$ & -mol/hr----- \\
\hline $\mathrm{H} 2 \mathrm{O}$ & 139539. & 0.0 & 0.0 & 0.0 \\
\hline $\mathrm{CO} 2$ & 0.0116893 & 0.0 & 0.0 & 0.0 \\
\hline HNO3 & 10644.1 & 0.0 & 0.0 & 0.0 \\
\hline N2 & 0.713642 & 0.0 & 0.0 & 0.0 \\
\hline 02 & 0.357478 & 0.0 & 0.0 & 0.0 \\
\hline FEIIIOH3 & $4.48756 \mathrm{E}-12$ & 0.0 & 0.0 & 0.0 \\
\hline NAHCO3 & $5.40774 \mathrm{E}-11$ & 0.0 & 0.0 & 0.0 \\
\hline NANO3 & 835.984 & 0.0 & 0.0 & 0.0 \\
\hline HGOH2 & $1.59434 \mathrm{E}-08$ & 0.0 & 0.0 & 0.0 \\
\hline $\mathrm{UO} 2 \mathrm{CO} 3$ & $1.98127 \mathrm{E}-11$ & 0.0 & 0.0 & 0.0 \\
\hline $\mathrm{UO} 2 \mathrm{OH} 2$ & $1.76965 \mathrm{E}-11$ & 0.0 & 0.0 & 0.0 \\
\hline OHION & $1.04965 \mathrm{E}-12$ & 0.0 & 0.0 & 0.0 \\
\hline CO3ION & $1.92945 E-19$ & 0.0 & 0.0 & 0.0 \\
\hline FEIII2OH2ION & $6.00529 E-04$ & 0.0 & 0.0 & 0.0 \\
\hline FEIIIION & 2031.54 & 0.0 & 0.0 & 0.0 \\
\hline FEIIINO3ION & 4427.6 & 0.0 & 0.0 & 0.0 \\
\hline FEIIIOH2ION & $6.50299 E-06$ & 0.0 & 0.0 & 0.0 \\
\hline EEIIIOH 4 ION & $1.03360 \mathrm{E}-22$ & 0.0 & 0.0 & 0.0 \\
\hline FEIIIOHION & 1.4709 & 0.0 & 0.0 & 0.0 \\
\hline HCO3ION & $1.23994 \mathrm{E}-09$ & 0.0 & 0.0 & 0.0 \\
\hline HGION & 120.949 & 0.0 & 0.0 & 0.0 \\
\hline HGOH3 ION & $1.04598 E-23$ & 0.0 & 0.0 & 0.0 \\
\hline HGOHION & $3.38400 \mathrm{E}-04$ & 0.0 & 0.0 & 0.0 \\
\hline HION & $6.65596 \mathrm{E}-07$ & 0.0 & 0.0 & 0.0 \\
\hline NACO3ION & $8.18605 E-21$ & 0.0 & 0.0 & 0.0 \\
\hline NAION & 348.207 & 0.0 & 0.0 & 0.0 \\
\hline NO3ION & 17911.3 & 0.0 & 0.0 & 0.0 \\
\hline UO2 $20 H 2$ ION & $3.47125 E-05$ & 0.0 & 0.0 & 0.0 \\
\hline UO23OH 5 ION & $7.31471 \mathrm{E}-18$ & 0.0 & 0.0 & 0.0 \\
\hline UO2CO32 ION & $4.96366 \mathrm{E}-26$ & 0.0 & 0.0 & 0.0 \\
\hline UO2ION & 1184.19 & 0.0 & 0.0 & 0.0 \\
\hline UO2OHION & 0.00224072 & 0.0 & 0.0 & 0.0 \\
\hline & $============$ & $============$ & $===========$ & \\
\hline$===========$ & & & & \\
\hline Total g/hr & $5.35363 E+06$ & 0.0 & 0.0 & 0.0 \\
\hline Volume, L/hr & 3468.22 & 0.0 & 0.0 & 0.0 \\
\hline Enthalpy, cal/hr & $-1.15818 \mathrm{E}+10$ & 0.0 & 0.0 & 0.0 \\
\hline Density, g/L & 1543.63 & & & \\
\hline Vapor fraction & 0.0 & 0.0 & 0.0 & 0.0 \\
\hline Solid fraction & 0.0 & 0.0 & 0.0 & 0.0 \\
\hline Osmotic Pres, atm & 737.584 & & & \\
\hline E-Con, 1/ohm-cm & 0.255605 & & & \\
\hline E-Con, cm2/ohm-mol & 24.297 & & & \\
\hline Abs Visc, cP & 0.895297 & & & \\
\hline Rel Visc & 1.24341 & & & \\
\hline Ionic Strength & 11.8306 & & & \\
\hline
\end{tabular}




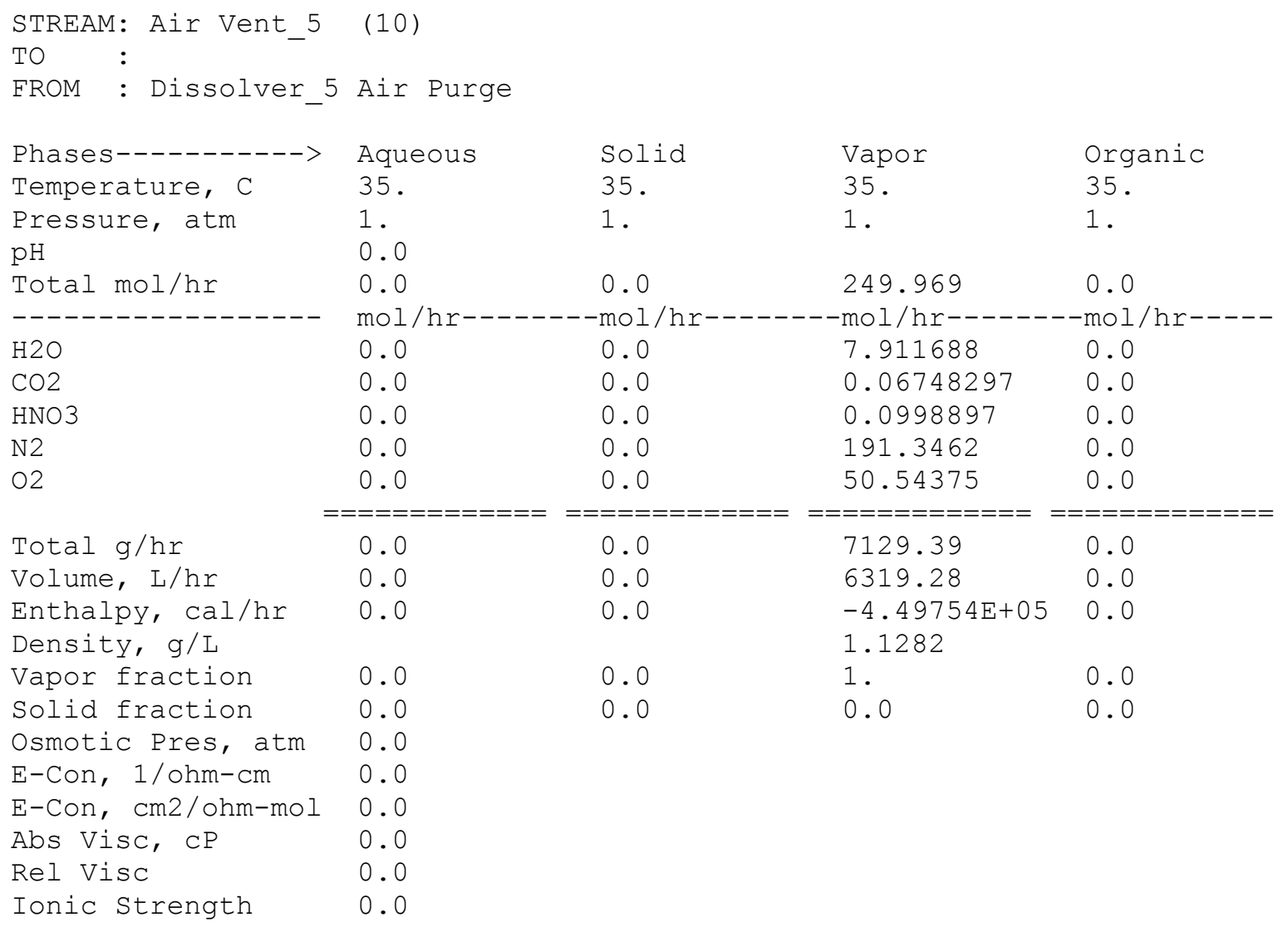




\begin{tabular}{|c|c|c|c|c|}
\hline FROM : Dissolver_ & 5 Air Purge & & & \\
\hline Phases-----------> & Aqueous & Solid & Vapor & Organic \\
\hline Temperature, C & 35 . & 35. & 35 . & 35 . \\
\hline Pressure, atm & $\begin{array}{l}1 . \\
-0.838662\end{array}$ & 1 . & 1 . & 1 . \\
\hline Total mol/hr & 177046 & 0.0 & 0.0 & 0.0 \\
\hline------------------ & $\mathrm{mol} / \mathrm{hr}------$ & $--\operatorname{mol} / \mathrm{hr}------$ & $---\operatorname{mol} / \mathrm{hr}------$ & $---\operatorname{mol} / \mathrm{hr}-----$ \\
\hline $\mathrm{H} 2 \mathrm{O}$ & 139539. & 0.0 & 0.0 & 0.0 \\
\hline $\mathrm{CO} 2$ & 0.0128771 & 0.0 & 0.0 & 0.0 \\
\hline HNO3 & 10644.2 & 0.0 & 0.0 & 0.0 \\
\hline N2 & 0.799636 & 0.0 & 0.0 & 0.0 \\
\hline $\mathrm{O} 2$ & 0.400394 & 0.0 & 0.0 & 0.0 \\
\hline EEIIIOH3 & $4.48747 \mathrm{E}-12$ & 0.0 & 0.0 & 0.0 \\
\hline $\mathrm{NAHCO} 3$ & $5.95724 \mathrm{E}-11$ & 0.0 & 0.0 & 0.0 \\
\hline NANO3 & 835.982 & 0.0 & 0.0 & 0.0 \\
\hline $\mathrm{HGOH} 2$ & $1.59432 \mathrm{E}-08$ & 0.0 & 0.0 & 0.0 \\
\hline $\mathrm{UO} 2 \mathrm{CO} 3$ & $2.18257 \mathrm{E}-11$ & 0.0 & 0.0 & 0.0 \\
\hline UO2OH2 & $1.76963 \mathrm{E}-11$ & 0.0 & 0.0 & 0.0 \\
\hline OHION & $1.04964 \mathrm{E}-12$ & 0.0 & 0.0 & 0.0 \\
\hline CO3ION & $2.12550 \mathrm{E}-19$ & 0.0 & 0.0 & 0.0 \\
\hline FEIII2OH2ION & $6.00520 \mathrm{E}-04$ & 0.0 & 0.0 & 0.0 \\
\hline FEIIIION & 2031.54 & 0.0 & 0.0 & 0.0 \\
\hline FEIIINO3ION & 4427.6 & 0.0 & 0.0 & 0.0 \\
\hline FEIIIOH2ION & $6.50289 E-06$ & 0.0 & 0.0 & 0.0 \\
\hline FEIIIOH 4 ION & $1.03357 \mathrm{E}-22$ & 0.0 & 0.0 & 0.0 \\
\hline FEIIIOHION & 1.47089 & 0.0 & 0.0 & 0.0 \\
\hline HCO3ION & $1.36593 \mathrm{E}-09$ & 0.0 & 0.0 & 0.0 \\
\hline HGION & 120.949 & 0.0 & 0.0 & 0.0 \\
\hline HGOH 3 ION & $1.04596 \mathrm{E}-23$ & 0.0 & 0.0 & 0.0 \\
\hline $\mathrm{HGOHION}$ & $3.38398 E-04$ & 0.0 & 0.0 & 0.0 \\
\hline $\mathrm{HION}$ & $6.65634 \mathrm{E}-07$ & 0.0 & 0.0 & 0.0 \\
\hline NACO3ION & $9.01781 E-21$ & 0.0 & 0.0 & 0.0 \\
\hline NAION & 348.208 & 0.0 & 0.0 & 0.0 \\
\hline NO3ION & 17911.3 & 0.0 & 0.0 & 0.0 \\
\hline UO22OH2 ION & $3.47119 \mathrm{E}-05$ & 0.0 & 0.0 & 0.0 \\
\hline UO230H5 ION & $7.31444 \mathrm{E}-18$ & 0.0 & 0.0 & 0.0 \\
\hline UO2CO32ION & $6.02358 E-26$ & 0.0 & 0.0 & 0.0 \\
\hline UO2 ION & 1184.19 & 0.0 & 0.0 & 0.0 \\
\hline UO2OHION & 0.00224071 & 0.0 & 0.0 & 0.0 \\
\hline & $===========$ & $==========$ & $===========$ & $==========$ \\
\hline Total g/hr & $5.35364 \mathrm{E}+06$ & 0.0 & 0.0 & 0.0 \\
\hline Volume, L/hr & 3468.22 & 0.0 & 0.0 & 0.0 \\
\hline Enthalpy, cal/hr & $-1.15819 \mathrm{E}+10$ & 0.0 & 0.0 & 0.0 \\
\hline Density, g/L & 1543.63 & & & \\
\hline Vapor fraction & 0.0 & 0.0 & 0.0 & 0.0 \\
\hline Solid fraction & 0.0 & 0.0 & 0.0 & 0.0 \\
\hline Osmotic Pres, atm & 737.585 & & & \\
\hline E-Con, 1/ohm-cm & 0.255604 & & & \\
\hline E-Con, cm2/ohm-mol & 27.3099 & & & \\
\hline Abs Visc, cP & 0.895299 & & & \\
\hline Rel Visc & 1.24342 & & & \\
\hline Ionic Strength & 11.8306 & & & \\
\hline
\end{tabular}

